\title{
Poderes del Juez Y Visión Cooperativa del Proceso ${ }^{1}$
}

\author{
C. A. Alvaro de Oliveira 2
}

1. No caben dudas que ei derecho procesal, como fenómeno cultural, constituye producto exclusivo del hombre, siendo por consecuencia inevitablemente ernpulgado por el concepto, un tanto concerniente, es verdad, de lbertad. Por eso, el tejido interno del proceso se forma por la confluencia de ideas, proyectos sociales, utopias, intereses económicos, sociales, políticos y estrategias de poder vigentes en determinada sociedad con marcas especificas de tempo y espacio.

Constituye, pues, un zrave equívoco, asimilario, a pesar de su carácter formal, a una simple ordenacion de actividades, dotado de cuño exclusivamente técnico, compuesto por reglas establecidas de modo totalmente arbitrario por el legislador. Ja estructura misma del proceso civil no es troldeada por la simple adapración técnica del instrumento procesal a un objetivo defindo, pero especialmente por opeiones de naturaleza politica, en búsqueda de medios más adecuados y eficientes para ha reaización de los talores, especialmente los de contenito constitucional. Esos valores, en realicad son los que estructuran la vida juridica de cada pueblo, de cada nación, de cada Estado ${ }^{3}$.

En esa perspectiva, el tema de los poderes del juez constituye uno de los mâs fascinantes de la dogmática procesal civil, porque se vincula estrechamente a la ráturaleza ya la función del proceso, a la mayot o a la menor eficacia de ese instrumento en la realización de sus objervos y, todavia, al papel que es atribuido al magistrado, en la

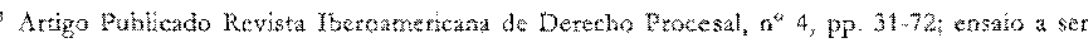

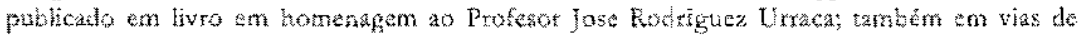

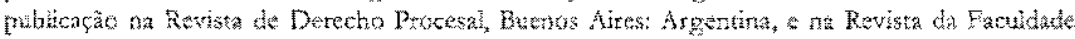
de Direito da Universidade de Lisboa.

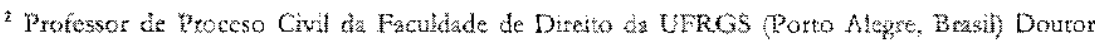
en Direto peta Universidado de Sao Paular.

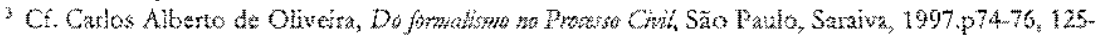
126, thasidy
} 
dirección y solución del proceso, en consonancia con los factores amiba mencionados.

Se impone, así, establecer una solución de compromiso, que permita al proceso Llegar a sus propósitos esenciales, en razonable espacio de tiempo y, principalmente, con justicia. Al mismo tiempo, importa estar atento para que el poder concedido al juez no redunde en arbitrio o comprometa su necesaria y imprescindible imparcialidad. En tal contexto, resalta con fuerza la etapa civilizatoria, la fuerza de las instituciones y del ejercicio de la ciudadania en determinada sociedad. Sólo llevándose en consideración esas variables, será posible apreciar la conveniencia de que sean o no reforzados los poderes del juez, engrandecidos o disminuidos los de las partes.

Toda esa discusión, pues, es influenciada al fin y al cabo por la justa y exacta ponderación de que cualquier simplificación procesal en el dominio de las formas, a mayor o menor libertad del juez, "non e posible se non in proporzione de/la fiducia che in un dato momento I'ordine giudiziario ispira ai cittadini"'. Confianza que sólo será adquirida si existir comprensión recíproca entre la ciudadania y la magistratura, eficiencia y competencia de ésta en el ejercicio de sus altas funciones.

2. En una visión de conjunto, todavia introductoria, se revela esencial tener: presente las dos más importantes concepciones en el trato del problema y sus desdoblamientos a lo largo de la historia del derecho procesal y las principales ideas desarrolladas a respecto. También es conveniente investigar si no es posible una tercera vía, que potencialice de modo más efectivo la realización del derecho material y la obtención de justicia, en tiempo razonable.

La concepción liberal, aún no imbuida claramente del carácter público del proceso, atribuya a las partes no solamenre amplios poderes para el inicio y finall mismo y el establecimiento de su objeto, como también sometía a la exclusiva voluntad de éstas su ritmo y desarrollo atribuyéndole total responsabilidad en lo que dice respecto a la propia instrucción probatoria. Los poderes del órgano judicial eran, pues significativamente restringidos.

Sintomáticamente uno de los más representativos exponentes del proceso civil del siglo XIX, época de total aceptación de este modelo, principalmente en razón de ser entonces concebido el proceso como institución destinada a la realización de derechos privados, marcaba producir el dominio de las partes sobre el objeto del litigio, su origen, continuación y contenido, justificando el principio dispositivo exclusivamente por la falta de interés del Estado en el objeto de la controversia ${ }^{5}$. Así como en otros campos, se creía en el libre juego de las fuerzas sociales, conquistando

4 CHMOVENDA, Prinquii di Diritto Procestuale, 4 ed, Napoli, Jovene, 1928, 43 II pág 664.

${ }^{5}$ ADOLF WACH, Conferencias sobre la ordenanza procesal civil alemana, trad. de ERNESTO KROTOSCHIN, Bs. Aires, Ejea, 1958, págs. 60-61 
cuerpo ha idea de que el prôpro interés de la parte litigante en el derecho alegato constututa efiente catalizador para la trás rópida inyestigación de la sinuacion juridica".

Hoy, sin embargo, cl carácter privado no corresponde más a la concepción dominante sobre la naturateza y la funcion del proceso civil pues ha experiencia ha desmentido ha crencia en la efcacia del trabjo desarrollado por los participantes de proceso". Es suficiente pensat en que la aplicación del pructipio dispositivo an su concepoton chisica, inponjendo exclusiva contribución de las partes en cl aporte al procese de la materia de hecho relativaza más alla de lo deseable de la apreciación de la verdad por el juez, Forzándole a contentarep pasivamente con la veraion traida por las partes. También restringe la libertad delorgano judicial, de mancma inconventente, la adopción del lamado sistena de prueba legal ante la rigida regulacion de la apreciación de la prueba, cayo rjemplo más completo es proveido por el derecho común.

Fri el extremo opuesto, sc pone la instivacion de un proceso civil para las relaciones de derecho privado con plena exclusion del principio dispositivo y abohto dominio de principio de la of cialidat en favor de amplia investigación de la verdad "real y objetiva", como ocurió en los parses del mundo sociatista, Jo gue ocakionaria la casi total absotción del derecho civil por el derecho público".

Realmente, la radicalización en exe rema puede implicat exagerada "publicización" del proceso, llevanio hasta a ha aborción de ha justicia en la administración como llegó a ser sugertdo en el plano doctritario en Alemania naztsta, con ilmitada atmbucion de poderes al juez en la investigación probatoria y consecuente enfinquecimiento de las gáantas y seguridad de los derechos individuales".

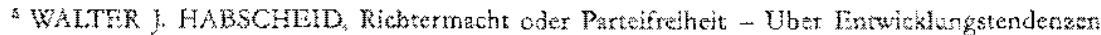
des modernen Zwilprozessechts, in Zainchift fur Ziviprozess, 81 (1968) $175-195$, efp pás. $186-197$

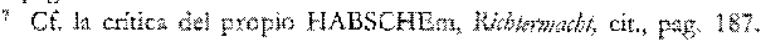

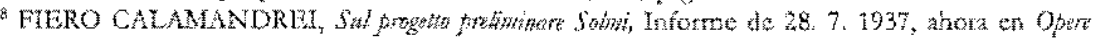

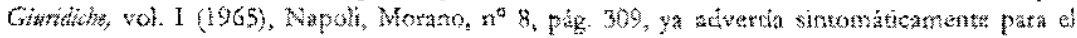
fenometo de abolición de detecho privajo en face de la exacerachen del principio

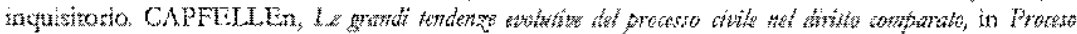

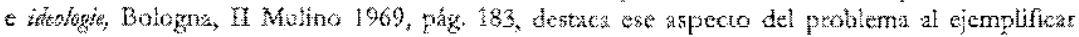

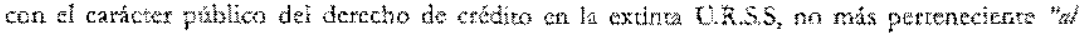

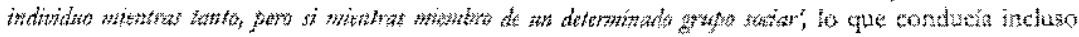

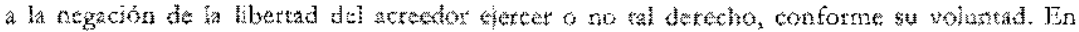

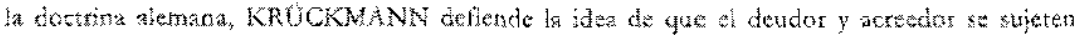

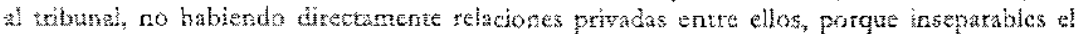
derecto privalo y el páblico, una vez que derecho privado no puede dejar de ser derecho

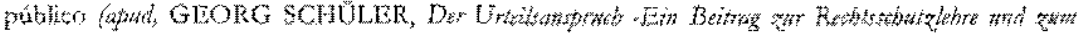

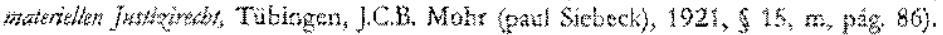

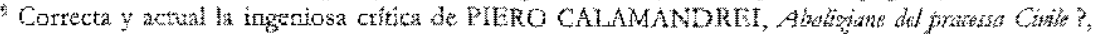

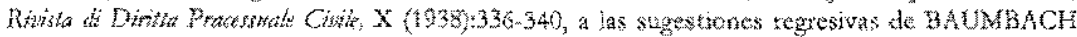

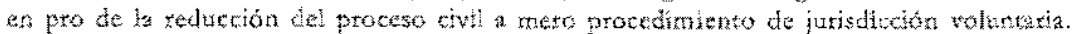


Acuerdese, también la teforma prusiana, bajo inspinación de FREDERICO II, EL GRANDE, a establecer amplia investigación oficiosa de los hechos por el juez en cualquier tipo de proceso. Igualmente, de manera contradictoria y sorprendente, aunque en postura ma contorate con el autoritarismo pristano, fuera retirada al magistrado cualguiar liberad para la apreciación de ia prueba adquitida

Sin embatgo, aunque con el empleo de esos antiguos procedimientos que contener en st, adenas, las desventias propias del proceso de tipo inquisitorio - no se puede tener la llusion de que la verdad material pucta sienpre ser alcanzada. Ya eso se viene agregar, principalmente desplés del fracaso fel socialismo real, cierro cepucismo en el aspecto de ha autorida y y de la tutela ofrecida pox el Estado, refutándose su intervención en la esfera de la autonomía privada atunque la dirección del proceso por el magistrado tenga por meta conducir la controversia de manera objetiva, de modo a alcanzarse en tempo tazonable a la emanación de un juico lo más cercano de laverdad).

La investigación de otro método de trabajo, más apropiado a la naturaleza del proceso actual, capaz de obtener mayor eficacia en in aplicación y realización del deredo, se identifica especialmente en la reforma procesal efectuada pot FRANZ KI.ENN en Austrata, al final del siglo XIX"

Después de subrayar el clevado concepto del valor social y público del proceso resultante de la historia, destaca KLEIN la necesidad de ser rápidamente extirpado, de manera más simple y barata ese auténtico "mal social" ("sozia Übel"). En ese contexto, los principtos procesales de la oralidad, de la publicidad y de habre valoración de la prueba, constituyen solo medios, técnicos diriamos nosotros, para atingree el propósito del proceso, enterdido éste como ayada segura e inmediata ("Gegenwatshife"), una indispensabie regia de bienestar social ". De esa premisa extrae sobre todo, la necesidad de la más aguda actividad del juez, solicitado a participar de forma más intensa en el procesoy en particulax en la investigán de los hechos. Se trata de confiarle diección efectiva y no solamente formal del proceso.

Declaradamente, la preocupación de KLENN se centraba en la idea de crear un proceso cixil en el cual la parte menos hábil, menos culta, menos dotada de recursos (cin posibilidad de pagar un defensor ficientc y capaz) viniera a encontrarse en pie de igualdad material y no solamente formal en relacion al adversatio. De ahi, el fortalecimiento de los poderes del órgano judicial a punto de se imponer a éste no

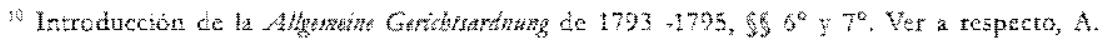

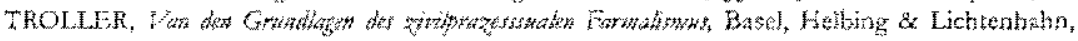
$10,5, \pi 5,2$, págs. 4446 .

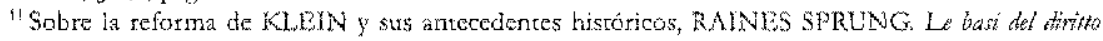

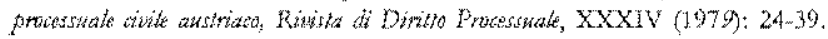

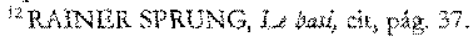


sólo la facultad pero igualmente el deber de advertir a los litigantes de las irtegularidades y huecos de sus pedidos y alegaciones, en el ejerco de una verdader función supletoria y auxiliar. El juez ultapasá, así, la posicion de mero anbitro fiscalizador de la obserwancia de las "reglas del iuego", para alcanzar status de acrivo participante, con vistas a evitar la pérdida de la causa por la escasa habilidad de la parte o de su representante.

Por eso, KLEIN consider el proceso civil una "Wohlfahrtsentichtung", o sta, un instituto destinado a promover el bienestat colectivo, considerándolo principamente como fenómeno social de masa, Sexía un error, pondera KLELN, pensar que la inactividad del juez y la actividad exchusiva de las partes constituirín en el proceso la ultima conclusión de tosal la sapiencia humanati,

Haciendose un análisis crítico de esa vistón social del proceso se impone advertir, en primer lugar, que aumento de los poderes del juez no debe significar, necesatiamente, completa indeterminación de esos poderes. De modo ninguno ha pretendida restauracion de la autoridad del poder estatal en el proceso habra de implicar tenuncia a se normaltivizar su desarrollo. Tal solución transferiria al organo judicial el poter de crear a su modo, caso por caso, la regla procesal más apropiada pata el desartollo del procedimiento, conduciendo a to tal indeterminación e impresibülidad. Se inctementaria, as de manera totalmente desnecesaria, el arbitrio del poder estatal dentro del proceso Sin embargo la función social del proceso, el exceso de poderes delorgano judicial podtia desembocar en un proceso esencialmente privado de formas, conducido según la libre discrecionalidad del juez, con probable perjuicio a la igualdad substancial de las partes y violación del principio de la certeza jurídica, sin hablar del eventual menosprecio al nexo entre el derecho material y el procesal.

Si KLLEN tenfa completa tazón al constatar que el proceso civil es integrado pox normas para la protección del interés de la colectividad y de los bienes jurídicos del individuo, imposible desconocer, pot otro hado, las garantias de los ciudadanos y de las personas en general contra el arbitrario e ilimitado ejercicio del poder estataly

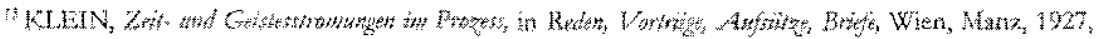

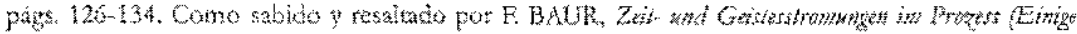

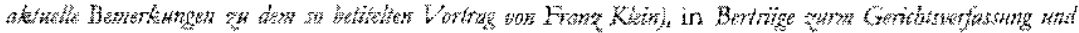
zuts a

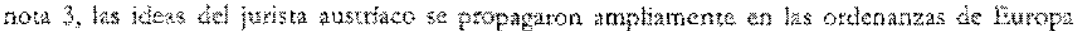

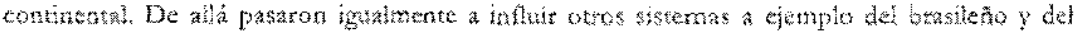

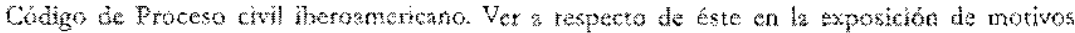

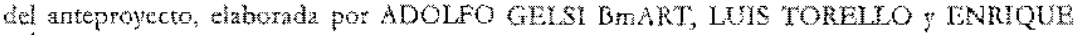

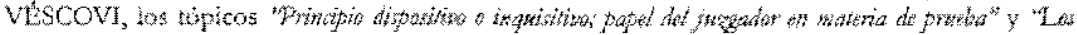

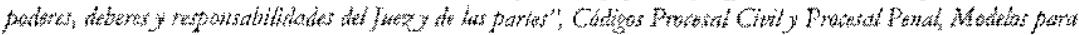

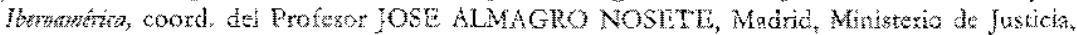

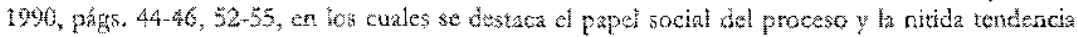
de intensincacion te los poderes del organe judictal.
} 
hasta el intecés del propio Estado en la realización de su derecho cbietivo, interés que también podria periclitar ante el arbitrio absoluto.

Al mismo tiempo no hay cono hacer rettroceder el activismo judicial resultante de la evolución social, politica y cuitural de nuestra época ya tomado "chase fate", y que realmente puede contribuir para la nâs acabada realización de la tutela jutisdiccional. Por señal Lnforme relativatmente reciente sobre el activismo judical extrae de la situación actual, dentro de esa linea de pensamiento las siguentes conclusiones: a) declina el sistema inquisitorial de tipo socialista, mientras aunentio de nanefa continua el poder del juez (en la dirección del proceso, en su ordenación yen el dominio de las pruebas); b) es conflmado, por casi todos tos relatores nacionales, el crecimiento del activismo del juez en su sistema procesal nacional, con manutención del principio dispositivo; c) se verifica un acercamiento de los sistemas angloamencanos y europeo

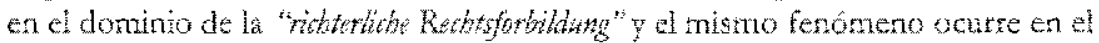
ambito del proceso; d) el activismo del juez se muestra petfectamente conciliable con el activismo de las partes, conscientes y cooperantes ${ }^{34}$.

Ese activismo en gran parte decurre de la tomada de conciencia de que el juez es también un actuante politico del Estado, portador del poder de éste y expresión tie la democracia indirecta ejercida en los estados occidentales contemporáneos, inexistiendo pues sázón para encerarlo en cubículos formales del procedimiento, sin libertad de movimientos y con poquisima libertad creativa ${ }^{\text {th }}$. El exceso de formalismo conducirfa, por otro lado, a la exaltación de las prescripciones formales como fin en sí mismo, de nodo manifiestamente incompatible con las finalidades sociales del proceso moderno ${ }^{3}$.

For otro lado, esas consideraciones ponen en el tablado de las discustones el propio paradigma de proceso civil hoy vigente entre nosotros basads en una concepción que induce el órgano judiéa a asumir una posición dominante y superor en relación a las partes y sus representantes, fundamertada especialnente en la autoridad, en La hicrarquia y en la lógica burocrática.

Para que el problema sea bien entendido se revela de gran importancia comparar el modelo tradicional de proceso de los dias que corren con la idea de iudicium vigente hasata el siglo XVIT.

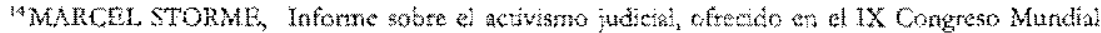

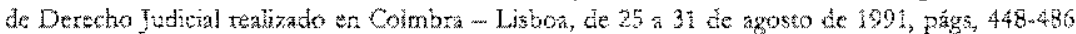
de los anzles.

"CANDIDO R. DINAMARCO, A instmontatitate do procesto, 2it ed, sno Paulo, RT, 1990, pág. 182.

"T.a observación es de LUUG Comogro, Direzione del processo e responsabiliti I del gudice in Rivista di Dirito Processuale, XXXI 11977 ) 14.56, esp. Pag 19
} 
El llamado ondo indituriuf cra hartamente influenciado por tas ideas expresas

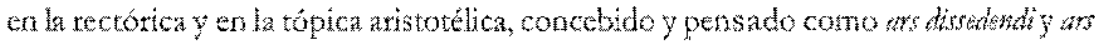
optonendi at perpondenati todo con vistas a resolver el problema, que ocupaba ci centro de la discusion. En la lógica de lo probable, previsto por a concepción, la investigación de la verdad no se presentaba como resultado de una razón individual, pero del esfuerzo combinado de las partes, revelándose implicita ana actiod de tolerancia en relación a los "puntes de vista" del otro y el carăcter de sociabilidad del saber. Como o iutaizan era impuesto por ha práctica judicial al margen de la autoridad cstatal, transcurriente solo de la elabovación doctrinatia, sin cualquier fundamento en regla escrita, reclamaba de manera intunseca una similitud y reciproca reglanentacón del diálogo judiciario". Esa "orden isonómica", y el punto es bastante importante, visaba a garantizar la iguadad entre gobernantes y gobernados, entre el juez y las partes y entre las propias partes ${ }^{14}$.

EI cambio de perspectiva, introducido por la lógica de PETRUS RAMUS (1515-1572) antecipa una alteración de direción que busca añadir al derecho los métodos propios de la ciencia de ia naturaleza, un pensasmiento dirigido por el sistema, en busca de una verdad raenos probable, con aspiriciones de certeza, a

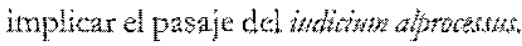

A partir del siglo XVIt el nuevo panorama metodológico se fortalece con la estatzactôn del proceso; con la apropiación del on thaticiatizis por el soberano, pot el principe, que pasa a reivindicar el nonopolio de la legislación en materia procesal, tendencia incrementada después por las ideas del luminismo y por el verdadero terremoto producido por la Revolución Francesa ${ }^{210}$. Se pierde, asis la dinension retónica del proceso Más que eso la intromisión estatal en el proceso judicial viene a reflejarse en los poderes del juez y el nuevo ordo presenta un curácter "asimétrico", privilegiando

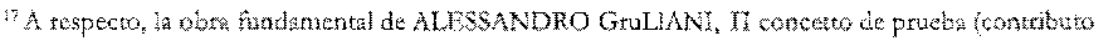

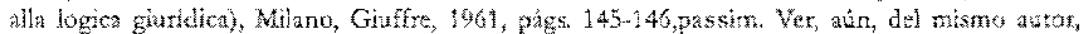
Logica del dirtto (teoria dellaromenaziont), Fnciclopedia del Dirtto, XXY (1975):13-34. Instigant: $y$ pot demás revetadot a admirabie sintesis de NICOLA PICARDI, Processo Civile (dir. madenoy, Encielopedia del Ditito, XXXVI (1987): 101-118. Dexde el punto de vista

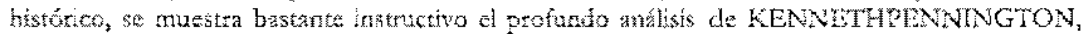
The Prince and the Law, 1200-1600, Soverigaty and Rights in the

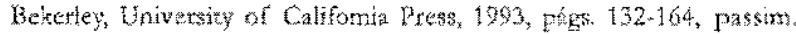

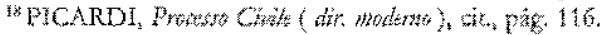

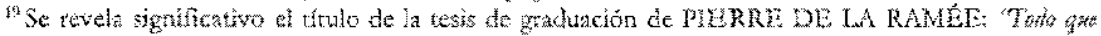

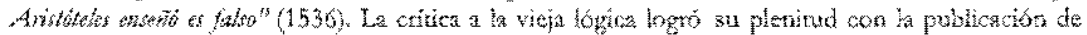

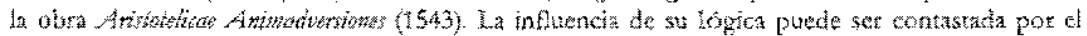

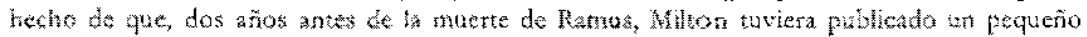

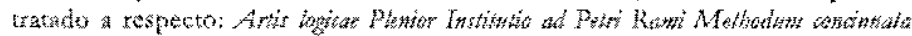

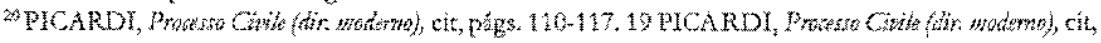
píg. 117
} 
la posición de la autoridad delante de los ciudadanos" , introduciendo un paradigna que solo actuanente, paso a ser puesto en faque.

Esa line de inflexion empiezas ganar fuera con la renovación de los estudios de lógca jurdica, a partir de los años cincuenta del siglox $x^{22}$, y con la énfasis prestada al sentido problemático del derecho, elementos que en clerta medida inician el rescate de la antigua dimensión retónica y dááctica del proceso. No se puede dejar de destacar que tal fenómeno ocurrió exactamente cuando -ya prenunciando el postmodernismo -más agudos y comprimentes se volvían los conflictos de valores y más inprecisos y flexibles los conceptos ${ }^{23}$.

Además, no se puede desconocer, hoy, que la aplicacion del derecho es basada fundamentainente en conceptos juridicos indeteminados, tales cono los principios. Por serial, el nuevo C6digo Civil brasileño, en vigor desde 11,1,2003, recurre constantemente a conceptos juridicos indeterminados y a jucios de equidad (vg, ants. $317,413,421,422,478$ y 9447 .

La colocacion del probiema en cl centro de las preocupaciones hermenétudas, con el empleo de lóvicas más adecuadas a la especificidad del fenómeno juridico y el frecuente empleo de principios, conceptos jurídicos indeteminados y juicios de equidad en detrimento de una visión tigurosamente formalista en la aplicacion del derecho, habría simplemente de se reflejat en el proceso. Ocure debido a esto, en primer lugar la recuperaeion del valor esencial del dáago judicial en la formación del juicio, que ha de fructificar por la colabotación de las partes con al organo judicial y de éste con las partes, conforme las reghas formales del proceso. El coloquio así estimulado, digase, deberas sustuir con ventaja la oposición y la confrontación, fando oportunidad al concurso de las actividades de los sujetos procesales, con amplia colaboración tanto en la pesquisa de los hechos cuanto en la valorización de la causa.

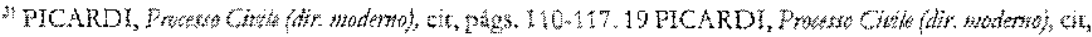
patg. 117.

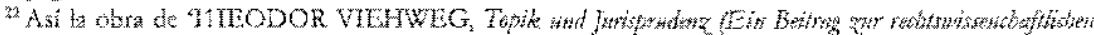

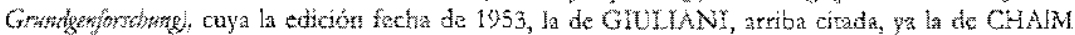

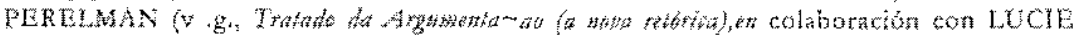

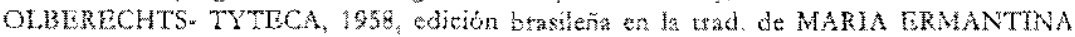
GALVAO $Q$. PERERA, sá Paulo, Marin Fontes, 1960 .

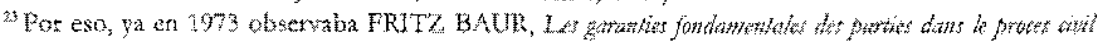

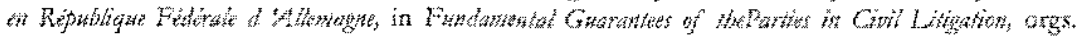
CAPPELLETT E TALLON, Milano, Giuffe, 1973 , pags, 3-30, esp. pág. 19, que "un sobrevaelo de la jurisprudencia do los triburates alemanes, en paticular del Tribunal constuciona faderal, en lo que tora al derecho de ser oido delante to kos twhunales, permite decte que ese aforisme ofrecto y siempte ofrece la posibilidad de parmity la aplicacion de los printiptos de tha proceso leal y justo, materia en que precismente las códigos de proceso son incompletos o con "agunas". 
Las diectivas aqui preconizadas son teforzadas, por otro lado, por la percepción de una democracia más participativa, con un consecuente ejercicio más activo de la cudedania, incluso de la catutaleza procesal.

Además, se tevela evidente la importancia de contradictorio para el proceso justo, principio esencial que se encuentra en a base misma del dialogo fudicial y de la

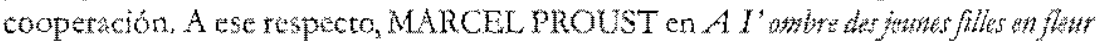
, con su apurada sensibilidad, subsaya de modo ejemplar que "una idea fiterte comunica un poco de su fuerza al contradictor. Como participa del valor miversal de los espiritus, clla se introduce en el spítitu de aquel a suien refita, on medio de ideas adyacentes, con ayuda de las cuales, retornando a huna ventaja, el la completa y rectica; tanto aś que la sentencia final es de algún modo obra de las dos personas que discutan ${ }^{224}$. En la perspectiva judicial, diria que la sentencia final sólo puede resultar del trabajo conjunto de todos los sujetos del proceso.

Ora, la dea de cooperacion adenás de implicar, si, un juez activo, colocado en el centro de la controversia, importatá el restablecimiento del carácter isonomico dé proceso o por lo menos ha busqueda de un punto de equibrón. Ese objetivo se impone alcanzando por el fortalecimiento de los poderes de las partes, por su participación más activa y leat en el proceso de formación de la decisón, en conformidad con una visión no autoritaria del papel del juez y más contemponánea cuanto a la división del trabajo entre é órgano judicial y las partes ${ }^{25}$. Aceptas exas premisas axiologicas, cumple apartar la incapacidad para el diálogo estinulada por a actual conformacion del proceso judtcial brasileno, asentado en otros valotes ${ }^{2 h}$.

No se trata bien entendido, de propianente restablecer el omb isonómico medieval, pero de inserir el proceso en la época post-moderna, de modo a legituarse plenamente el ejercicio de la jurisdicción mediante nejor y más acabada comuncicán del órgano judicial con los actores del proceso y por la busca de un razonable equilutio de los poderes det juez en relación a los poderes de las partes y de sus representantes ${ }^{27}$.

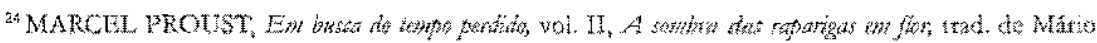
Quintana, 2. Ed, Potto Alegra, Globo, pag. 107. La propla concepcion da la garantía del contradictorio no se muestra contratia a la idea de un procest civil cooperatwo, cf. C. A.

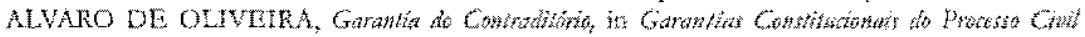

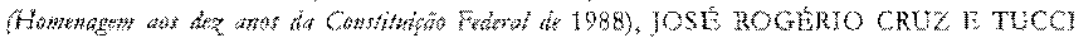

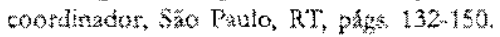

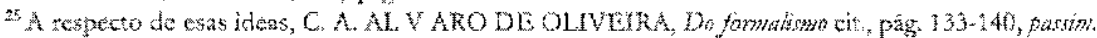

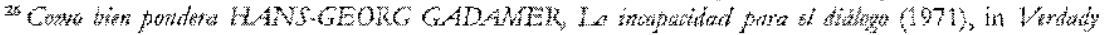

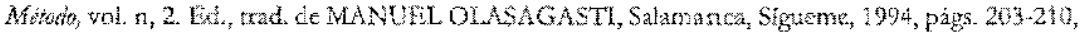

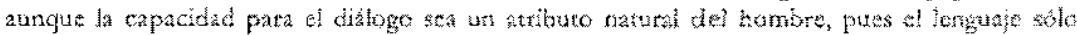

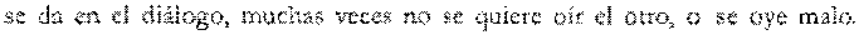

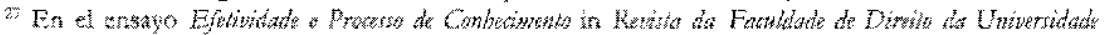

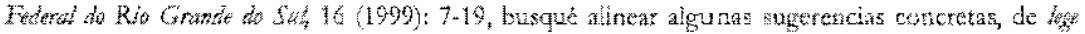

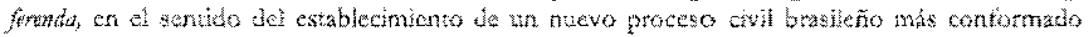
a los valones mencionados en et texto. 
Dentro de esos balizamientos, se pautó la notable alteración introducida en el Código de Proceso Civîl portugués por los decretos ley $329-\mathrm{A}$, de 12 de diciembre de 1995 y 180 , de 25 de septiembre de 1996 , a adoptar como meta el principio de cooperación, y la reforma del proceso civil francés inspirada por al informe COULON DE $1996^{24}$, destacando el equilibrio y el diãlogo.

De ahi ha necesidac de establecerse el pemanente concurso de las actividades de los sujetos procesales, con ampplia colaboración tanto en la pesouisa de los hechos, cuanto en la walorización jurídica de la causa ${ }^{29}$. Colaboración esa, se destaca fortificada por permanente dílogo, con la comunicación de las ideas proporcionadas por cada uno de ellos: juicios históricos y valotizaciones jurídicas capaces de ser empleados oportunamente en la decisión ${ }^{30}$. Semejante cooperación, se resalte, se justifica todavia más por la complejidad de la vida actual.

Entendimiento opuesto padeceria de vicio dogmático y positivista, sobre

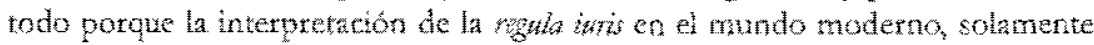
puede nacer de una comprensión integrada entre el sujeto y la norma, generalmente no univoca, con fuerte carga de subjetividad. Y esa contestación todavia más reforzada pro el reconocimiento de que todo terecho litigioso se presenta incierto de forma consubstancia!.

Exactamente, en face de esa realidad, cada vez más pesente en la rica y conturbada sociedad de nuestos tiempos, en cambio permanente ostentándose inadecuada la investigación solitaria del órgano judicial. Todavia más que el monólogo reduce necesartamente la perspectiva del observatox y en contrapartida el diálogo, encargado por la dialectica, amplia el cuadro de análisis, constrine a la comparación, atenu el peligro de opiniones preconcebidas y favorece la formación de un juicio

${ }^{2}$ JEAN-MARIE COULON Retlexions et propositions sur la proctedure civile in Rapport at garde des Sceaux, ministre de la Justice, Paris, 1907, donde ste destata (pág. 13) que "Le mâtre

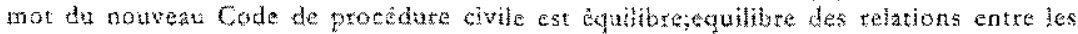
purties et le juge, égullobre des intérêts en présence guj touxe sa pleine expresión sans le contradictone, säns cesse "siaffumb"

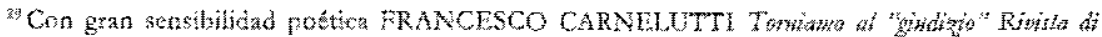

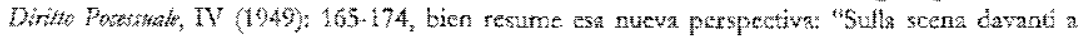

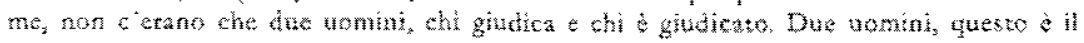
problema. Due fratelli: questa è la soluzione "

w Fi, EDUADO GRAS5O, La Collaberazione ne Processo Civile, in Rivita di Dirito

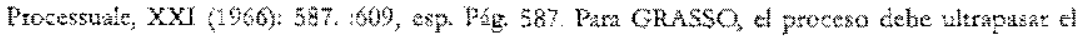
simple objervo de la paz jutidica, debiendo tambien set drefcionado a la búsecued de la verdad y de la justick objetivos súlo alcanzados segun él, arediante la colabonación entre las partes. 
más abierto y ponderado ${ }^{31}$. El perniso concedido a los litigantes de pronunciarse e intervenir activamente en el proceso imposibilita, también, se sometan pasivamente a la definición juridica of fóctica de la causa efectada por el órgano judicial. y descarta, por otro lado, el tratamiento de la parte como simpie "objeto" de pronunciamiento judicial, garantizando su derecho de actuar de manera critica y constructiva sobre el ritmo del proceso y su resultado, desarrollando antes de la decisión la defensa de sus razones. El tema se vincula al propio respeto a la dignidad humana ya los valotes intrinsecos de la democracia, obteniendo su meior expresión y teferencial, en el ámbito procesal, en ei principio del contradictorio, comprendido de manera renovada, y cuya efectividad no significa sólo discusion de las cuestiones entre las partes, pero conereto ejercicio del derecho de defensa para fries de fomación del convencimiento del juez, actuando, así, como protección a las lagunas o insuficiencia de su cognicion.

Mismo la iniciativa del óngano fudicial en el campo de los poderes instructorios debe ser sospechosa en un cuadro de dimensiones măs amplas, de nodo a permitr la adecuada fomación del convencimiento del izgadot. Inadnzisible, por tales razones, se sometan los litigantes pura y simplemente al impulso del órano judicante ya su anhelo en llegar a una correcka definición de la causa ${ }^{32}$, o se linite este á apáticanente recoger el resulado de la actuación de las partes. Al contratio del juez dictador, dueño de un proceso inquisirorio y autotitatio o de mi proceso totalmente dominado por las partes, como precalion al abittio estata - a ejemplo del ocurtido en la Edad Media con el proceso romano-canónico, importa principamente el ejercicio de la ciudadanía dentro del proceso, indice de la colaboración de las partes con al fuez, igualmente actwo, en la investigación de la verdad e de la justicia.

No se trata, pues, de superar la idea de KLEIN, e sí de darle otra forma mediante el necestrio foralecimiento de los poderes de las partes, dentro de una visión más contemporánéa del problema ${ }^{33}$. Y, relmente, en los cuadros de esa dirccén,

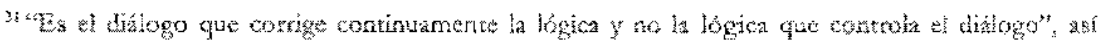

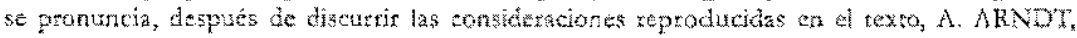

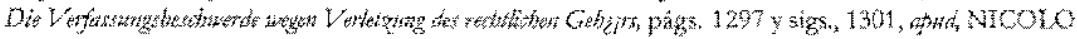

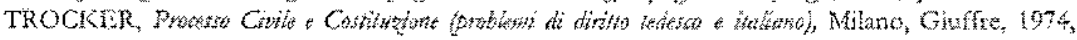

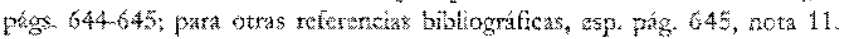

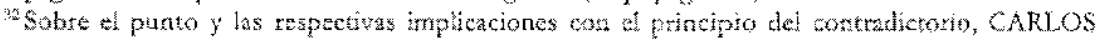

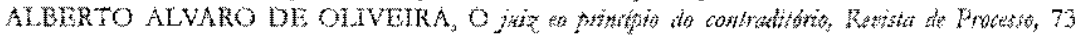
(195): 7 7 - 14.

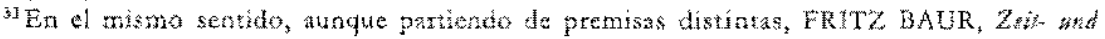

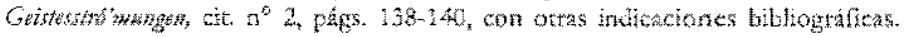


parece háber hoy consenso cuanto a las lineas del apogeo del proceso posmodemo en ese comienzo del siglo XXI, desartollándose para lo que se estipuló lamar de máxima de la cooperación (Kuoperationsmaxitha) arriba mencionada ${ }^{34}$.

Puestas esas prefnisas, paso a investigar como se compontan, en el cladro de una visión coopetativa dul procese, la apreciacion del dutecho, tas cuestiones ligadas a la pruebr de las alegaciones ya ha apreciación de los hechos, bien como el limite formal representado por el principio dispositiva.

3. Exactamente porcue ha función judicial se encuentra profundamente ligada a la apticación del derecho, se ha mantenido más o meros lineal en el curso de la historia la atribución concedida al órgano judicial de decir el derecho aplicable al caso levado a su consideración. Se trata aquí de interés de carácter general, circunstancia a posibilitar al juez a inyestigación y aplicación de las reglas furidiras adecuadas al caso sin ringún riesgo de parcialidad.

La solución tradicional, ya presente en el derecho tomano, se expresaba en las

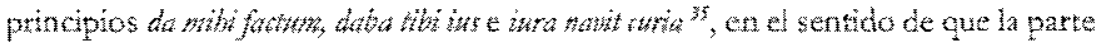
deberia 'suscitar el hecho juridico del cual decurriera su derecho y el órgano judictal aplicanta el derecho a ese hecho. La máxima, por otro hdo, costó a fijarse en los sistermas juridicos occidentales, tomándose operante sólo en el siglo $X V$, tanto que en la especulación medieval la cuestión de derecho no pertenecía al dominio de to

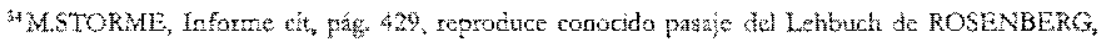

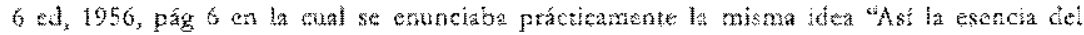
proceso civì moderno reside en una comunidad de trabajo (Arbeitsgemeinschaft) entre al jues $\mathrm{y}$ las partes, que unidos deben preocuparse en facilitar al primero, la segura obtención de la verdad y restabelecer en un procedimento vivo la paz jurídica entre las partes litigantes, "segurando de esn mancra ia paz de la comunidad"

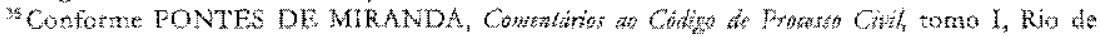

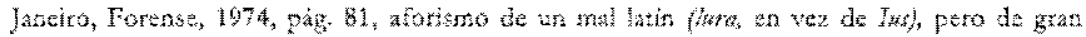

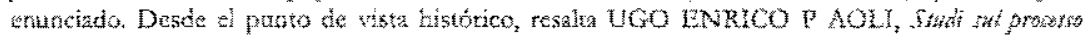

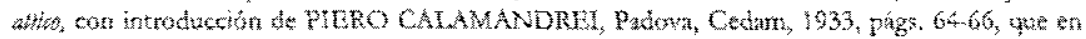

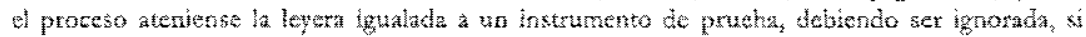

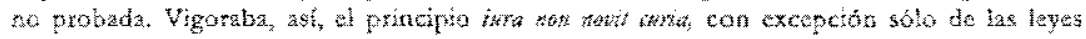

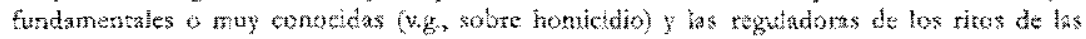
audiencias, aplicables de oficio por el magistrado conductor del proceso. Aunque extuvieta ch fucgo la busca de una solución de equidad para la ciusa, permitiendo aun la aiegación de leyes extranjeras, no se prescindia de su prueba para actarar la situatión de derecho, permitir la formación de un raciocinio abstracto sobre lo justo, o servir de apoyo a la equidad de la tesis sugerida por la parte. 
correcto, pero de lo problable. Toda ciencia del cerecho se reducia, entunces, a una ciencia de la prueba, y el propio derecho no existia independentemente de ella ${ }^{36}$.

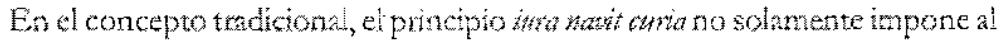
juez $z^{37}$ conocer el derecho e investigario de oficio, caso no lo conozca, pero tona tambita el crano judicial completamente independiente en su aplicacion, desvinculándolo de los pedidos y alegaciones de las partes a respecto. Nilaceptación de la existencia de determinada norma jutidica, ni la investigaton de su sentido y contenido, nila subsunción de los hechos introducidos en el proceson pueden ser impuestos por las partes al juez. De tal manera, cuanto a la posicion de la norma jurdica el juez ha de atenerse estrictancote a la raludad (del orderi juridico): "Fogude

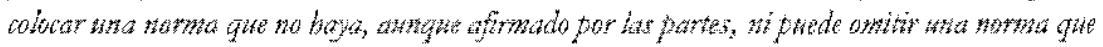

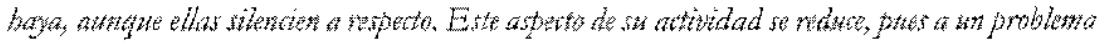

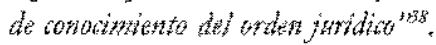

Por otro lado, mismo estando los litigantes de acuerdo cuanto a latidad de determinado negocio, propuesta la cemanda es licito al organo judicial, en el aspecto

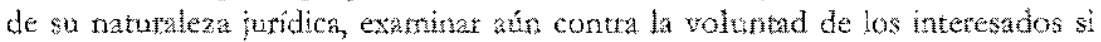
ocurio violación a las buenas costumbres o a la buena fe o si sería usuravo. Por eso, no vincula el juez un ajuste de las partes sobre el aspecto de caracter jutidico. Éste siempre podrá axtraer del material fáctico constánte del proceso las condusiones juridicas no aportadas por las partes ${ }^{34}$.

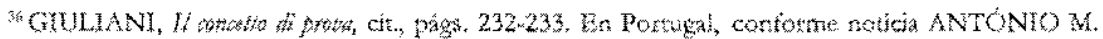

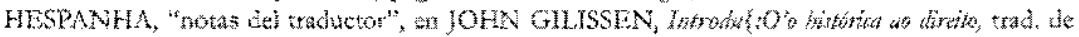
A. M. HESPANHA y L. M. MACASTA MALHEROS, Libbo, Gulbenkan, 19de, pag 720, ei principio sólo se consolide a partir del siglo $\mathrm{XV}$, con limícaciones para los esses da privilegios

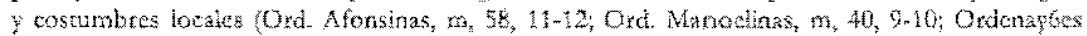

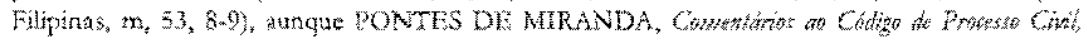
tamo I, ct. pag. 81 , alirme ser traicional en et detecho lusobrasileño.

"Cf. por todas, LWO ROSENBLRG, Dia Veranderung tes rechlicien Gesichtspunkts in

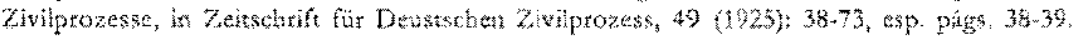

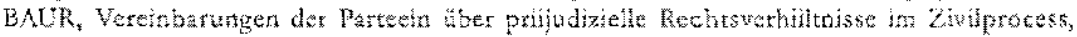

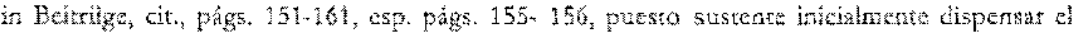

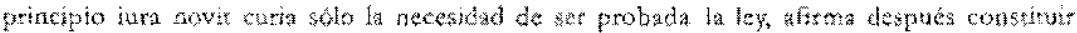
deber del juez irvestigar "la verdadera situacion jurdica", tesaltando con acierto zue esta debera aperarse dentro del chadro litigloso formato entre las partes.

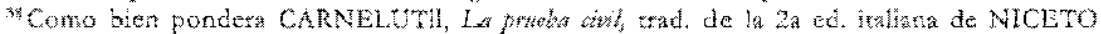

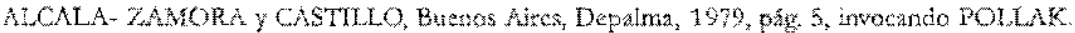
${ }^{39}$ tiste es el entendimiento tratietonal de la toctring aleman, expreso por WOLFGANG

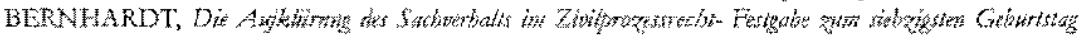

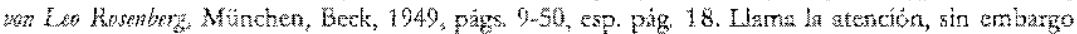

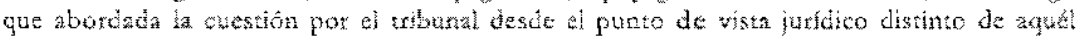

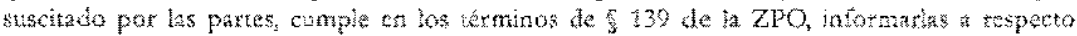

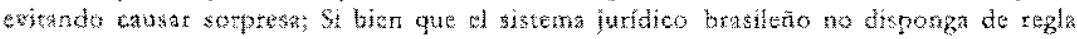
semeiante, a reio parecer ése deber es inerenta al propio principio del contradictorio, 
Bastante relevante, también, se muestra la importancia de la libertad atribuida al juez en la aplicación del derecho, pues actua como instrumento de gran valía para el equilibrio de las partes y garantía de la "paridad de armas", en la medida en que la ignorancia del derecho, su desconocimiento o errónea interpretación pueden frustrar la tutela juilsdiccional ${ }^{40}$.

Dentro de la visión cooperativista, antes resaltada, nada obstante a la libertad disfrutada por el órgano judicial en la valoración jurídica de la realidad externa al proceso, pueden y deben las partes aportar su cooperación a respecto. Investigación de esa especie de ninguna manera puede constituir, hoy, trabajo exclusivo del órgano judicial.

Se explica, por eso, la intervención del contumaz en el proceso, a pesar del reconocimiento ahi implicado de verdad de los hechos alegados por el autor (CPC, articulo 322,28 parte). Yeso porque la contumacia se restringe a la materia de hecho, con abstracción de las cuestiones de derecho, en relación a las cuales se permite a la parte buscar persuadir el órgano juagador. Del ius fomecido por los propios litigantes, y no solamente por el juez, trata expresamente el artículo 300 del CPC, determinando competir al reo, en la contestación, la alegación de toda la materia de defensa, "exponiendo Las ragones de becho y de derecho". En la misma línea, se admiten alegaciones de las partes sobre cuestiones de hecho y de derecho ( $v$,g, artículo $454, \$ 3^{\circ}$, del CPC).

Entendimiento contrario significaría transformar el juez en una máquina, pues como ya se resaltó con intensidad, dentro de una concepción puramente silogística, el juez diría a las partes date mibi factum ya las leyes date mibi jur y, recebidos tales elementos, emitiría la decisión con mecánica indiferencia, como un aparejo emisor de bilhetes a toda introducción de dos monedas ${ }^{41}$.

La expectativa del éxito final en la causa evidencía, en verdad el interés primordial de la parte en dar conocimiento al tribunal, consonante su interés, de la norma jurídica a ser aplicada: Lo mismo se pasa en relación al convencimiento del órgano judicial sobre la adecuación de la solución jurídica preconizada. Y eso porque puede

garantía asegurada en el artúculo $5^{\circ}, \mathrm{L}$ V, de la Constitución Federal de 1988, como penso tener denostrado en el ensayo O Juiz o princitio to contraditorio, cit., passim. Conforme FRMIZ B.AUR, Vereinburnngen der Parteein, cit., pág. 156 , pueden las partes vigorando el principio dispositivo, celebrar acuerdos sobre relaciones perjudiciales con carácter imposióvo para el juez, rechazando con todo la posibilidad de vincularlo sobre materia probatoria o obligario a una deteminada visión jurídica de los hechos. Ya CmOVENDA, Principii, cit., $\$ 47, \mathrm{~m}$, pág. 720 , advertia no haber límites para la actividad jurídica del juez (itura novit curia), asegurando la imposibilidad de ser restringida por acuerdo de las partes.

${ }^{4}$ C. ROBERTO BERIZONCE, Informe argentino presentado en el IX Congreso Mundial de Derecho Judicial, pág. 14, apud, MARCEL STORME, L'ativisme, cit., págs. 433-434 y nota 1.

${ }^{41}$ GUIDO CALOGERO, La logica del giudice e il sho controlto in cassazione, Padova, Cedam, 1937, $\mathrm{n}^{\circ} 37$, págs. 108-109. 
habet el reseo, mismo tratandose de derecho nacional, tiesgo ese intensificado por la complexidad de la vida modema, del juez no "descubrit" la numa furidica favorable allitigante, 0 de no interpretatia correctamente ${ }^{42}$,

En tal camino, la colaboracion de las partes con el jucio encuenta su tarón de ser en un proyecto más amplio, en la medida en que no se cuida sólo de investigar la noma aplicáble al caso concreto, pero de establecer su contenido y alcance, no solamente evitando sorpresas pero tambien las consecuencias negativas de ahi transcurrientes para ej ejercico del derecho de detensay de ta tutela de oros valores, como la concentración y rapidez del proceso y la calidad del pronunciamiento fudiciat ${ }^{43}$,

No se trata, sin embatyo, de un onus de la parte, pues si, de la fralta de enunciación de la regla juridica, adecuada para la solución del caso, ni siempre decur re

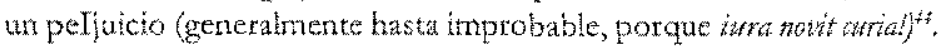

Adenás, no es admisible que los litigantes stan sorprendidos por decisión gue se apoye, en punto fundamental, en una visión juridica por ellos no percibida. El tribural debe, pues, dar conocimiento previo de cual direccion el derecho subjetvo corre tiesgo, aprovechando sólo los hechos sobre los cuales las partes tengan tomado posición. De esa maneta, las partes estarán mejor preparadas para defender su derecho e influir en la decision judiciat ${ }^{45}$.

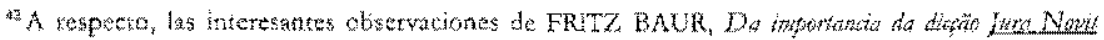

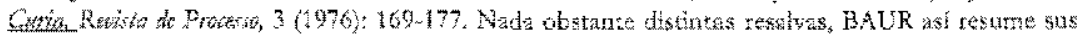

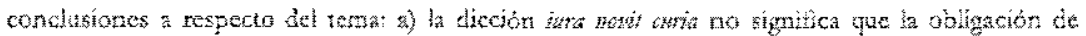

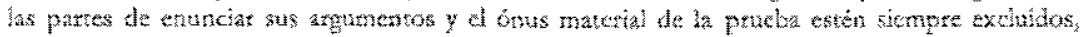

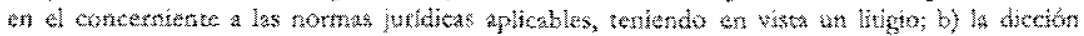

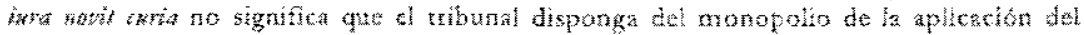

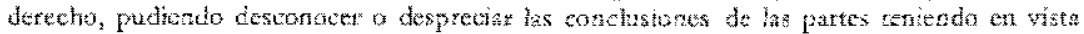

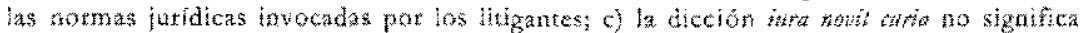
pertenceer al tribunal el derecho de hacer abstración de la ley, en funcién de referencia hecha a los principios de equidad, menos apropiados a la solución del litigio.

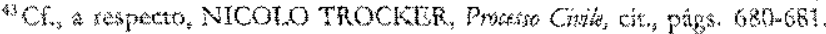

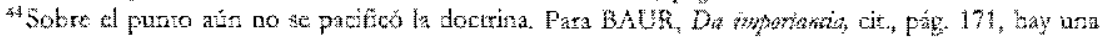

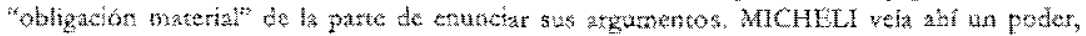

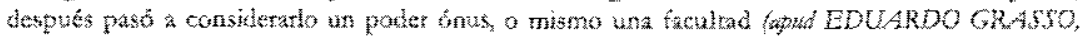

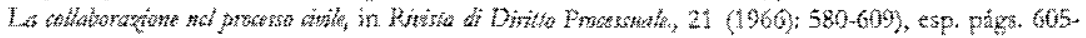

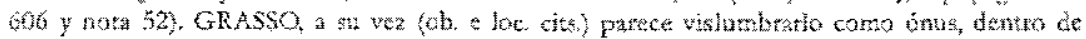
Su perstecriva especial del printipio de la colabonatón. Según JAMES GOLDSCHMDT, Der

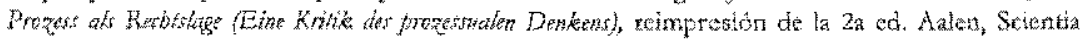
Verlas 3986 , pág. 425, no son siquicta afirnaciones, ni objeto de un ónus formal de aflemación, pero de actos de obtencion en sentido amplio y hasta participaciones de conocimiento.

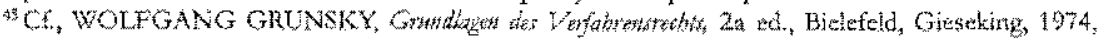

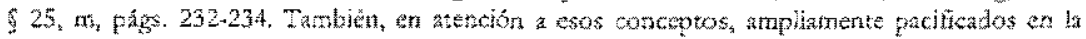
doctrita $y$ en la jurispruzeacia de la entonces Memariz Federal, cuando de la reforma

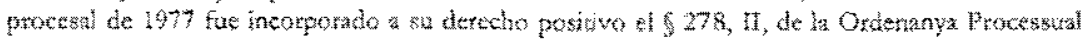

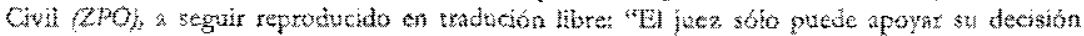


Dentro de la misma orientación, la libertad concedida al juzgador en la elección de la norma a aplicar, independentemente de su invocación por la parte interesada, consubstanciada en la máxima iura novit curia, no dispensa la previa oída de las partes sobre los nuevos caminos a ser impulsados al litigio, en homenaje, aún aquí, al principio del contradictorio ${ }^{46}$. La. hipótesis no es poco común porque son frecuentes los impedimentos enfrentados por el que aplica el derecho, ni siempre de fácil solución, dificultad generalmente agravada por la posición necesariamente parcializada del litigante, a contribuir para impedir una visión clara a respecto de los futuros caminos del proceso.

También la problemática no dice repecto sólo al interés de las partes, peto se conecta íntimamente con el propio interés público, en la medida que cualquer sorpresa, cualquier acontecimiento inesperado, sólo hace disminuir la fe del ciudadano en la administración de la justicia ${ }^{47}$.

El diálogo judicial y la cooperación, arriba preconizada, se toman en el fondo, dentro de esa perspectiva, auténtica garantía de democratización del proceso, a impedir que el poder del órgano judicial y la aplicación de la regla iura novit curia redunden en instrumento de opresión y autoritarismo, sirviendo a veces a un mal explicado tecnicismo, con obstrución a la efectiva y correcta aplicación del derecho ya la justicia del caso.

4. Más complicado y en constante modificación se revela el problema del papel a ser desempeñado por el juez en la investigación de los hechos y su apreciación, cuestión íntimamente vinculada a la división de trabajo entre el órgano judicial y las partes. La cuestión, por largo tiempo, fue tratada en conjunto y hasta confundida con el liamado principio dispositivo.

Ya son milenarios los conocidos aforismos "da mibi factum, dabo tibi ius" y "quod non est in actis, non est in nundo", a obligar el juez a sentenciar, como se expresaban los glosadores, "secundum allegtlla el probala" y no "secundum conscientiam" "*\$8. Tal concepción adviértase, nada tenía a ver con el problema del libre convencimiento del

en un aspecto juridico considerado insignificante por la parte, o que le tenga pasado desapercebido, si le ha sido dado oportunidad de se manifestar a respecto, salvo cuando tratarse de una cuestión meramente accesoria." Adoptó la tesis el $2^{\circ}$ Grupo Civil del Tribunal de Justicia de Río Grande do Sul, en la sentencia de la acción rescisoria 595132226, 10.5.1996, tedactor para el juicio el Juez JOSÉ MARIA TESHEINER, con substancioso voto vista del juez ARAKEN DE ASSIS, Revista Fornse, 338 (abril, mayo,junio/1997):301-309.

${ }^{46}$ Véase, aún aquí, GRASSO, La collaborayione nel procerso cinile, cit., pág. 605. Sobre el tema, con otras indicaciones bibliográficas, CARLOS ALBERTO ALVARO DE OLIVEIRA, O juiz to o principio do contraditórió, cit., págs. 10-12.

${ }^{47}$ Cfla certera ponderación de NICOLO TROCKER, Processo Civile, cit, pág. 669.

${ }^{46}$ Cf. WETZELL, System, cit., $\$ 43$, págs. 520-523, con amplio examen de la doctrina de los glosadores. 
juez, pero con la "ciencia privada" de los hechos por el magistrado, tanto que el

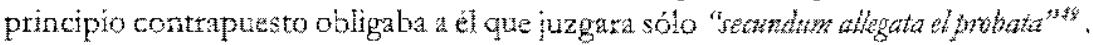

La aplicación extremada de esta concepción de la división del trabajo entre los suictos procesuates impone no solamente a inadmisibilidad del conocimiento o de la ciencia privada del juez cuanto al hecho, como tambien sea considerado tan sólo el hecho alegado por las partes y por ellas probado, con los medios que tequetiren.

El derecho procesal moderno, sin embargo, viene constantemente evolucionando en el sentido del ablandamiento de la última restriccion, de modo a liberar el juez de esas cadenas formalisticas atribuyéndole poderes intensificados para la investigación probatoria, facultándole de consiguiente mejor conocimiento de los hechos, punto importante en la furnación de su convicción. Dentro de esa nueva perspectiva, propuesta a la denanda y delimitades sus contomos esenciales, constituye deber del juez controlar lo rápido, regular y leal, desartollo del proceso, asumiendo incluso los medios probatorios, dentro es claro de los límites fácticos extremados por la parte actora para la causa

En ese terreno, cumple señalar, además de la mencionada teforma de FRANZ KLEIN en Austria, en fmes del siglo XIX, otra más antigua y bien menos comentada, Cdealizada por BPLLOT.

Al elaborar el proyecto del Code de Pratutum Civile del canton de Ginebra, ley sancionada en 29 de septembte de 1819 , ese jurista tuvo la glorsa de la pximacia de sacat el juez de la posición pasiva en la investigación de los hechos de la causa, que hasta entonces ocupaba. BELIOT era movido no por la preocupación con la tardanza del proceso, como sucediera con el legiskador prustano, pero sobre todo por el deseo de estimular la búsqueda y la investigación de a verdad material. Emblemático, en este sentido, el articulo $150 \mathrm{del}$ Code facultando al juez, si la causa estaviera aún sin

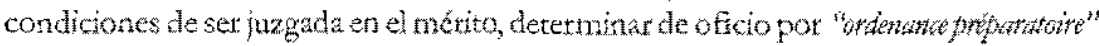
cinterrogatorio de las partes o de una de ellas, jutamento, oida de restigos, pericias, examen de documentos y inspecciones, o cuatquicr otro acto procesal probatotio

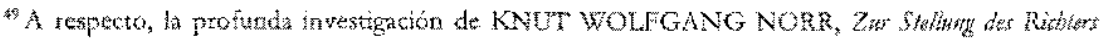

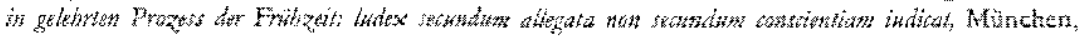
Beck, 196 ?, págs. 11 y sigk, 102 y sigs, paskim.

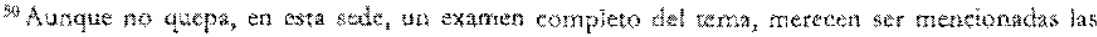

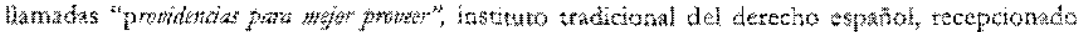

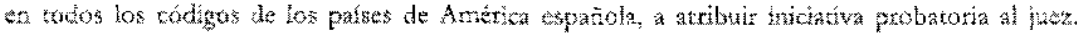
Señalan, sin erbatgo, ADOLFO GELSI BMART, LUTS TORELLO y ENRIQUE VLSCON,

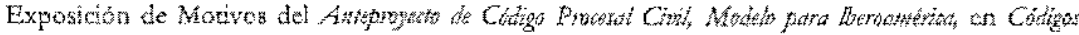

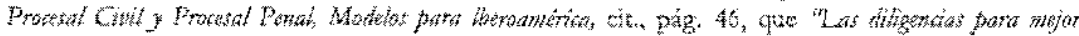

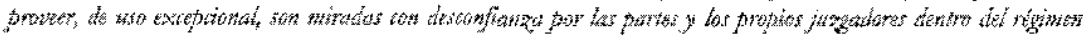

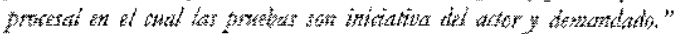


previsto en ley, en materia no adarada de modo suficiente después de realizada la instrucción, cuando necesario a la investigación de ba verdxd. "st",

La elabomaion dogmatica más reciente busca establecer las bases doctinatias para esa intervención del ơrgano judicial en el piano facticoy en la chabotación de la prueba. Impormante, partu ese fin, se presenta la constatactón de gue el proceso, aunque predestinado a la tutela jurisdictional de los dorechos, se arma de exigencias propias, imponiendo a sus participantes udaptación a siz mecanismo interno, ordenador de sus actividades.

Ocurre de ahi la necesidad de distinguir, sin embargo la recíproca influencia entre unas y otras, entre normas, poderes, deberes, facultades y sobre todo actos teferentes a pedido de tutela jurisdicoionai, y nomas, poderes, deberes, facultades y actos correpondientes a la técuica ya la estructura interna del procedimiento. Cuando

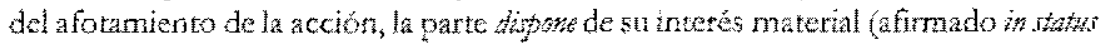

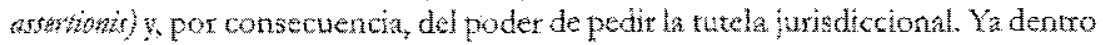
del proceso, se toman las iniciativas, especialmente de contentito probatorio, a la vista de la tomita propia del instrumento procesal, en la medida de su adecuación con la

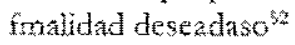

Sin embargo, de ningún modo pueden ser confundidos el momento inicial, consistenre en la alegación de los hechos juridicos, que dan sustraro a la pretensión sub judice, con el momento posterior, interno al proceso, concerniente a las demostraciones de cuño probatorio. El primero, cumple aclarat, no se agota tan sólo en una declaración de carácter informativo, pero en una duclaración de voluntad, que estrabece el elemento esencial del derecho o del contaderebo -el elemento constutivo causal-, con el cual ha parte actaa o se opone al actuar bo otra persona, vinculando el

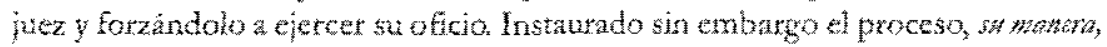
nitwo e imotro escapan a la disponibllidad de las partes, elementos que deben ser disciphados por normas logules cogentes, no siendo desprecinble sin enbargo pueda ejuez en ciertas hipotesis llevar en consideración las exigencias concretas del caso. De

${ }^{4}$ Cf. TROLLER, Formatismus, cit, $\$ 5,1$, pá. 47. Reza el mencionado artículo 150: "Dans les causes ou le fond ne sera pas en état detre juge de sulte (articulo 101), les juges pourront

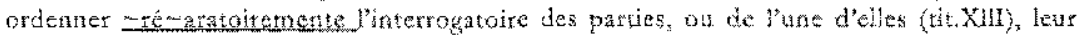

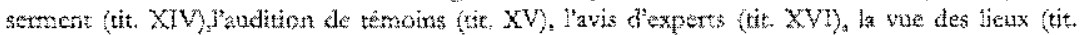

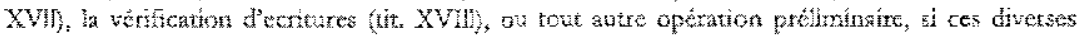

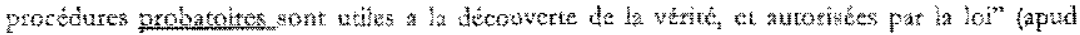

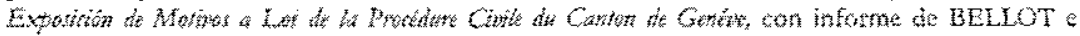

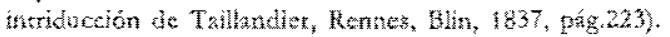

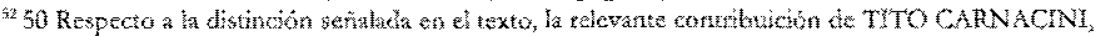

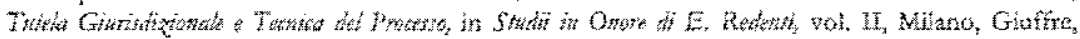

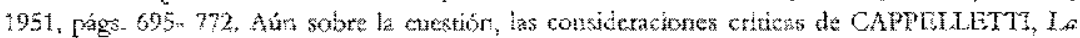

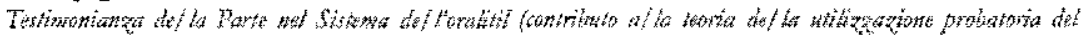

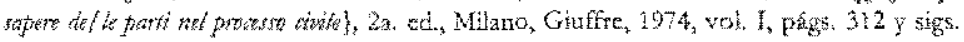


ahí, el equivoco de ponerse en el mismo plan a las iniciativas del fuez en tema de

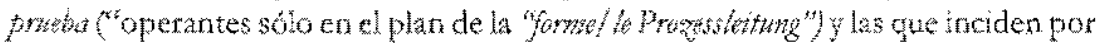
su vez sobre las alegtabtus, que conciemen efectivamente al plan de la "materia" o sea al "objeto" del proceso".

En realidad, la confusión impedirí la necesaria distriocion entre los planes del derecho materal y del procesal. En el primero, la faculad de inciar la demanda y fiat su contenido es dejada al exclusivo arbittio de los sujetos del dereche, cualquiera que Sea la naturaleza de la fretensión material. Al órgano judicial no se ototga poder para hacer cesar ha demanda o modificar el pedido o la causa de pedir, por eso tal actividad comprometeria imemediablemente ta imparcialidad propia de su oficio. En el segundo, vinculado de modo inextricable al propio ejercicio de la función jurisdiccional, al interés publico exige proterida la decisión sólo cuando formada la convicción del juez, asentada ésta lo más posible en la verdad de los hechos, porque en ejercicio de tarea propia de su oficio, debiendo el legislador establecer como se procesará tal investigación, disciplinando del mismo moda los poderes instructorios del juez.

Las consideraciones hastah ahora desarrolladas se muestran suficientes, desde mi punto de vista, para evidenciar el no comprometimiento de la parcialdad del magistrado con la asunción de los medios probatorios, desvio êse que, además, podrá ser perfecamente controlado por lo contradictorio, deber de motivación y posibilidad de reexamen de la decisión en segundo grado de jarisdicçón.

Todo, por consiguiente, recomienda la quiebra del monopolio de las partes en la lnsrucción de la causa, mismo tratandose de intereses puramente privados, pues no hay por que alterar la estrucura de proceso en funcion de la naturaleza disponible ondisponible del derecho litigioso $0^{54}$. Insustentable continuarse tolerando el jucz inerte, con los brazos cruzados, y que encaraba el proceso como cosa exciusiva de las partes ${ }^{35}$.

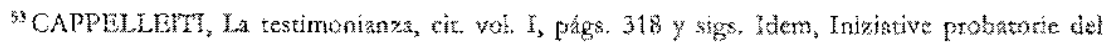

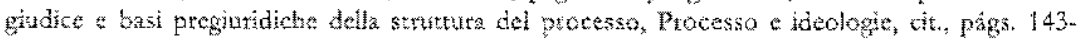
168, esp. págs. $152 \times 153,155$ y 157 , nota 25 .

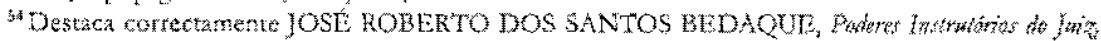

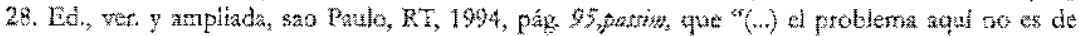
disponbilitad o indispontbilidad del interes, pero de un instrumento con gua el Estado

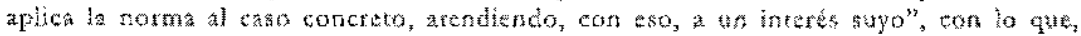
concediendose poderes instructotios al juez, se subtrue de la parte el poder de dirección formal tol proceso, pasando ella a condición de colaborabora del oryan judicial En esa obra por vatios títulos adminalis, el autor, poseido con bibliografa the la nejur calldad, examina

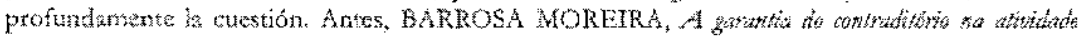

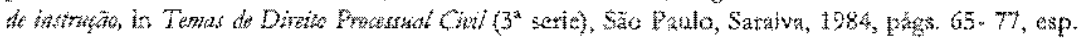

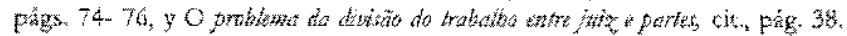

Según los artículos 130 y 342 del CFC, no sobo puede el juez determinat de oficio las pruebas necesarias $y$ denegar las diligencias in titles o meramente prenogatorias como también el 
En la visión cooperativista defendida en este ensayo, cumple señalar, sin embargo, que sin la colaboración del abogado mismo el juez más competente no estará enteramente habilitado a conducir un proceso complicado desde el punto de vista práctico. Aún con la mejor buena voluntad, le faltará tiempo y el mismo interés de los representantes de las partes para clasificar el material por éstas traido, procesarlo y formarlo con independencia ${ }^{56}$. De tal suerte, aunque lícito al órgano judicial actuar sponte suya con vistas a corregir los hechos inverosimilmente expuestos o suplir huecos en la materia de hecho, la iniciativa de las partes puede exibir valor inestimable y merece ser estimulada de modo a posibilitar la nás rápida y segura verificación del material probatorio. Vuelta al escenario, así, la necesidad de cooperación tantas veces mencionada: la actividad probatoria habrá de ser ejercida por el magistrado, no en sustitución de las partes, pero juntamente con ellas, como uno de los sujetos interesados en el resultado del proceso ${ }^{57}$. Claro está, sin embargo la total diversidad de intereses entre el órgano judicial y las partes. El proceso civil no actua en el interés de ninguna de las partes, pero sí por medio del interés de ambas. El interés de las partes no es sino un medio, un estímulo, para que el Estado, representado por el juez, intervenga y conceda razón a quien efectivamente la tenga, concomitantemente satistaciendo el interés público en la actuación de la ley para la justa composición de los conflictos ${ }^{58}$.

Se contrapone que si el juez determina, de oficio, con absoluta libertad, el tipo de prueba a ser producida y lo bace en el momento procesal que le convenir estará jugando por tierra toda la posibilidad de apreciación de los hechos bajo el prisma de la dirección dada por la carga de la prueba (o hacerse cargo de las consecuencias de

comparecirniento personal de las partes, a fin de interrogarlas sobre los hechos de la causa. En la práctica judiciaria brasileña y de otros países, sin embargo, consonante obsetva BARROSA MORERRA, sobre a sarticipafáa "do juiz no processo cinit, in Participuläo e Processo, coord. de ADA PELLEGRINI GRINOVER, CANNDIDO RANGEL DINAMARCO Y KAZUO WATANABE, sao Paulo, RT, 1988 , págs. $380-394$, esp. pág. 384 y respectiva nota 4 , se verifica escasez de iniciativas instruetorias oficiales, aún cuando manifiesta la conveniencia de aclarar cuestiones de hechos relevantes en que se muestran insuficientes los elementos de prueba traidos por las partes.

${ }^{56} \mathrm{CF} . \mathrm{LEUCH}$, apud TROELER, Fomatismur, cit. $§ 5$, pág. 76.

${ }^{57} \mathrm{Cf}$. la sintesis feliz de BEDAQUI, Poderes instrutórios, cit, pág. 110. Ln realidad, esa posición no está muy lejos de aquella asumida por VICENTE MIRANDA, Poderes do jhiz to procisso civil brasilein, sao Paulo, Saraiva, 1993, págs. 217-218, pues aunque sostiene éste la imposibilidad del magistrado sustituir la actividad de las partes en el campo probatorio, admite la actividad probatoria oficial cuanto haya imposibilidad de formación de la convicción del juez cuanto a los hechos de la causa y en materia de orden público. El punto de discordancia incide en el carácter imputado a la actividad probaroria del juez, no condicente totalmente con la visión cooperativista sostenida en el texto y también en la obra de BEDAQUL.

${ }^{53}$ Cf. EMILIO BE1TI, Diritto Processuale Civile italiomo, $2^{\mathrm{a}}$ ed., Roma, Foro Italiano, 1936, $\$ 1.2$, pág. 5 , señalando con total pextinencia que "Lo scopo di ciascuna delle parti e di aver ragione; la finalita del frocesso, invece, e di dar ragione a chi tha effettivamente." 
opción por no producita) o podra con bastante frectencia desacatar la ocurrencia de preclusion ${ }^{59}$. La asertiva desconoce, sin enbargo, por un lado, el verdadero sentido de dogma de la carga de la prueba, destinado como regla de juicio a permitir la solución de ha controversia solanente cuando no suficientemente probados los hechos, hipótesis posible hasta en proceso de corte exclusivamente inquisivivo , y tropieza, por otro, con el entendimento generabado en el sentido de inexistencia de preclusión tocante a la inciativa judicial ax of frnalidad debe consistir en mejor formar la convicción del ótgano juzgador, materia de oxden púb lico concentente a la propia actividad jurisdiccionat ${ }^{6}$. Sin embargo, si los medios probatorios son emplezos sin éxito, émpone la aplicación de la regla de jucio que es y al mismo titmpo freno contra el espititu de lingiosidad de las partes ${ }^{62}$.

La verdad es que, frente a la tomada de conciencia cuanto al inafustabic carácter dialectico del proceso, se cambio de forma significativa talcance dé antiguo axioma

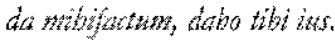

Antes de nada, se presenra algo atbitario valorat abstactamente la disquisicion o dincto sobre el hecho, como se totalmente divorctados del jucto de derecho No solamente se exibe artifial la distinción entre hecho y dexecho-porque en ditigio hecho y derecho se interpenetran ", peró pierde fuerza sobre todo en el tema ora en

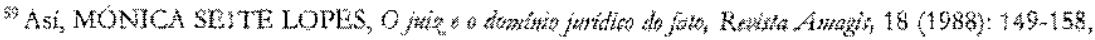
esp. pág. 155 .

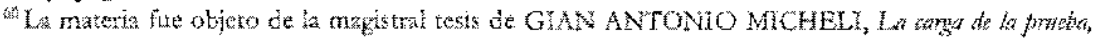

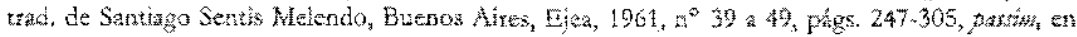
que no solo se cstablece el verdadero concepto de la carga de la pruzba, como tambion que "ft

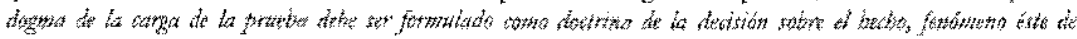

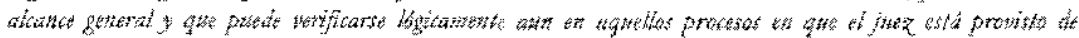

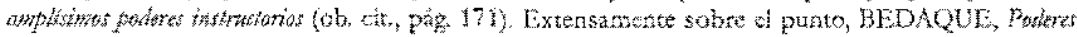

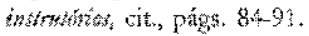

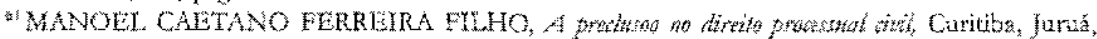

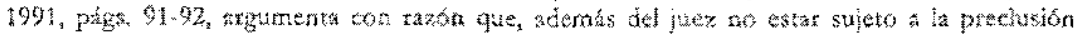
temporal, el artido 130 no le establece ningh plazo. Sin trmbargo aunge atmita que el poder de inichatra probatoria hacluye el de dereminar la produccion de prueba ya denchada, sostiene coryectamente que, si ta parte ejercố zregulamemte fa facultad y ruvo su petito aratado, a la posterioz denegacho de la prueba implicaria a a gatantizado constitutionalmetate.

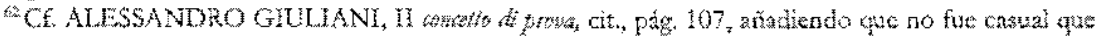
tal principio tenga sido puesto en evitencia en la exa trodema, curndo se viene afirnanó la

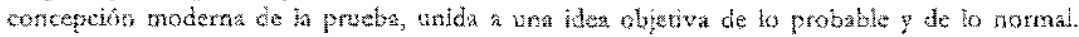

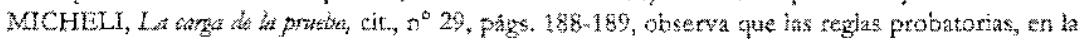

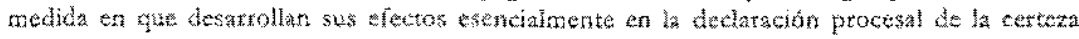

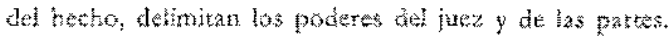


examen, en virtud de la necesidad del hecho en la construcción del derecho y de la correlativa indispensabilidad de la regla jurídica para determinar el relieve del hecho ${ }^{65}$

Ademas, se muestra evidente la relatividad de la primera parte del aforsmo. La indicación del material fáctico de la causa dejó de constitur tarea exclusiva de las partes. Ciertamente, deben ellas contribuir con los hechos esericiales, constitutivos de la causa fetendi, como arriba se señaló. No es reconendable, sin embargo, prohibir la apreciación de los hechos secundarios por el juez, de los cuales podrá, directa o indirectamente, extraer la existencia o modo de ser del hecho principal, sea porque consten de los autos, por ser notorios, o pertenecteren a la experiencia común ${ }^{t 4}$. Conveniente, aún, sea procesada la apreciación de los hechos prinepales por iniciativa exclusiva del órgano judicial cuando se refietan: a) la situación de derecho público o de orden público (asi, vig, la materia concerniente a los presupuestos procesales ya las llamadas condiciones de (a acción), b) a hechos juridicos extintivos e inpeditivos, incompatibles con la pretensión ejercida ( $v$ g., paga, confusion ctc), salvo si representativos de verdadera excepeion en sentido sustancial ${ }^{65}$. y esto sin bablar de los hechos constitutivos, modiffcativos o extintivos del derecho, capaces de influir en

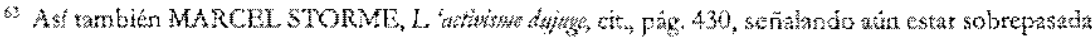
la distacion entre hecho y derecho, especialmente en el concernienc a lat division del trabaipo

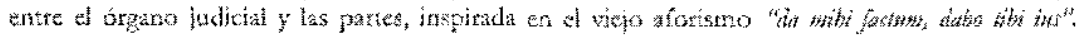

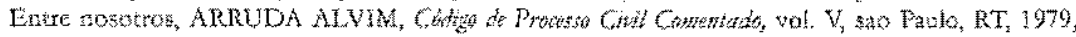

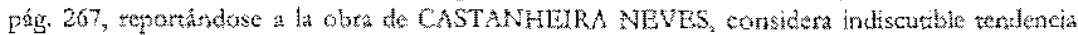

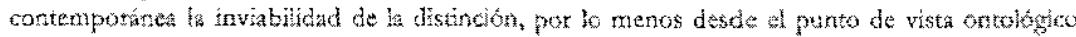

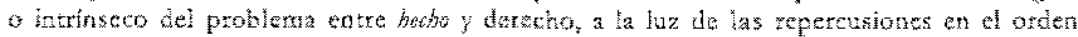

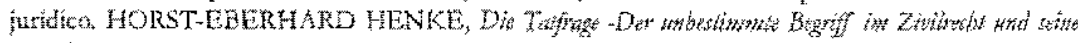

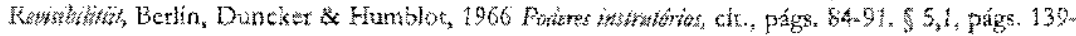
142 , se indina en el sentio de una imperiosa separatön lígico-conceptual entre "cuestión

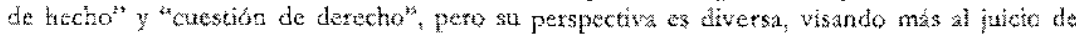
casacion.

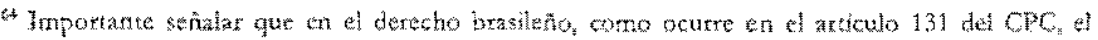

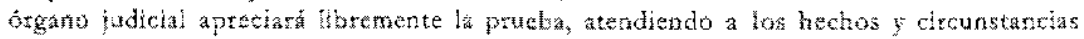

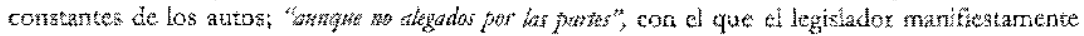
tomó partido por la pesibilidad del juez hasta de oficho, llevar en consdutacion hechos sectudarios. La doctina de todo genezal conceprus camn hechos secundarios aguellos

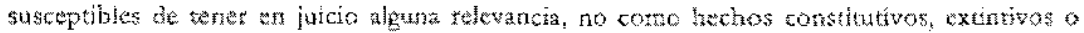

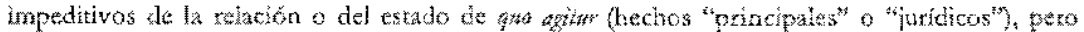
hechos de los cuales, directa o indirectamente, pueda deducirse la existencia o inexistencia o el modo de ser de los bechos juradicos.

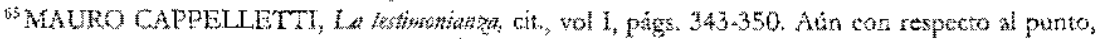

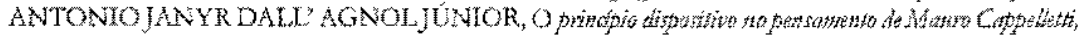

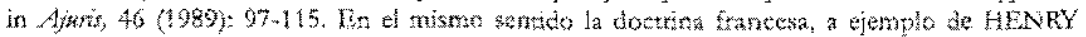

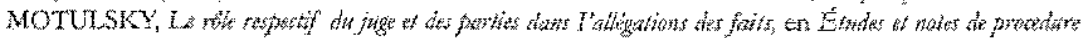

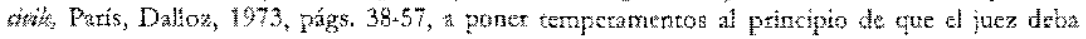
basar su decision exclusivamente en los hechos resulamente introduedos por las partes. 
el fuicio del litugio pastbies de consideración por el juez hasta de oficio en el momento de profetrita sentencia ${ }^{66}$.

5. Otro punto extremamente sensible concemiente a los poderes del juez se une a la valotación del material fáctico recogido para prueba de las alegaciones de las partes, materia que en el curso de la historia ha sido objeto de regulación ora más ora menos rigurosa, de molde a restringir of failitar la libertad del órgano judicial en el desempeño de tal tarea, en consonancia casi siempre con la confianza en ell depositada y los valoes imperante en la epocat?

En su modelo ideal más acabado el sistema de la prueba legal significa la minuciosa determinanción de los criterios de apreciación de la prueba ya ha vez limitación o exclusiơn a promion de deterninadas pruebas, la gue se sub trae crédito formal ante el magistrado, con vistas a testringix al maximo falbertad judiciats.

En los ordenamentos nuâs remotos, a ejemplo del antiguo proceso germánico, el sistema de la pruéba legal reflejaba un enratado sentimiento de superstición mistica, incumbiendo al juez la exciusiva función de controfar con su presencia la regularidad de las pruebas, de modo agarantizar acatamiento al resultado alcanzado por medio de la autoridad propia de su ofcio. Ninguna relevancia exibia entonces la conviceion judicial, pues era creencia general de gre la propia divinidad decidia sobre justicia e injusticia en la pruteba de la cruz ${ }^{*}$.

s. Alberga esa solucion el artículo 462 det $\mathrm{CPC}$.

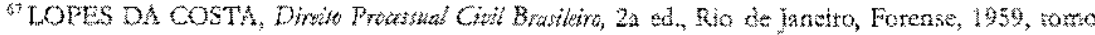

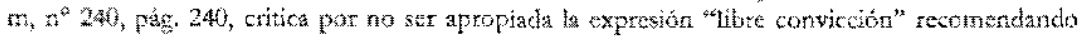
en su lugat "libre apreciación de la prueba". A su vex, la contraposición entre convicción libe y conviceión lorzada refleqa an contrascatida. Fueras os convenir, pera, gue convicción libre

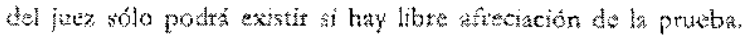

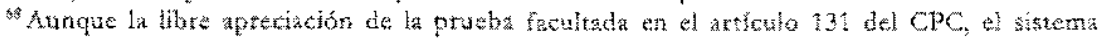

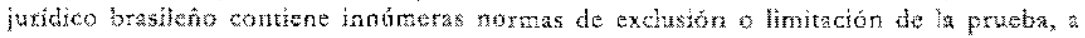

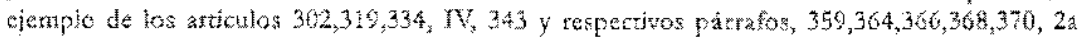
parte, 373,376,378,379,401,406 y restectivos partafos, todos det CPC. Otro ejemplo es lit

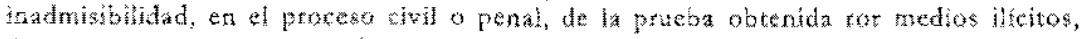
detexminatud por el artoulo 5 , intiso I VT, de la Constucion Federal.

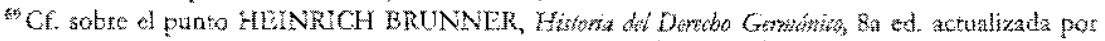

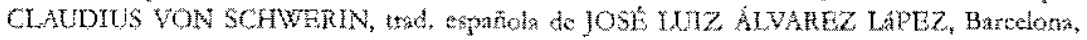

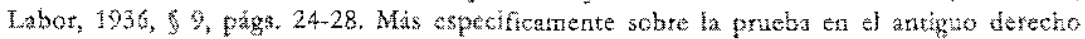

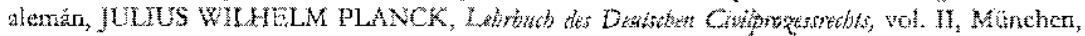

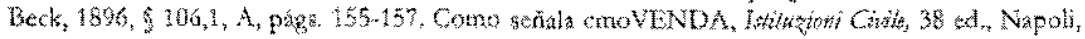

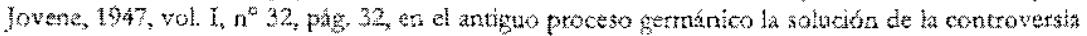

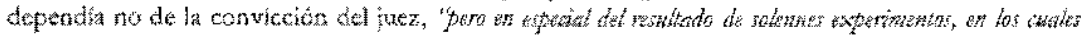

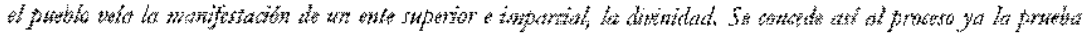

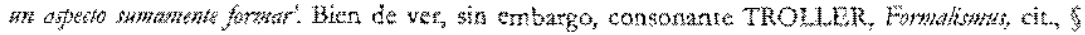
5.1, pág. 33, goe th ese proceso al juez desempenaba papel totalmente distinto del juez actrat,

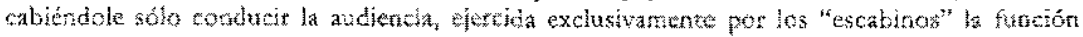
futidatmental de aplicacion del detecho. 
Significativamente, port más de quitientos años la praxis de los procesos italianos toservó y conservó prncipios esenciaimente peculiares al antizuo proceso germaticico?

La evolución histórica volvió a atribuir al juez, a partir del siglo XII, con ha

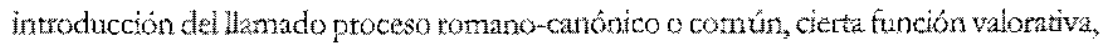
limitand sin embargo su libertad de juicio, observación y críca persona". Semejante Fomalisno fue fuertemente infuldo por la fragmentación del Estado y la deblidad de la idea de juristiccion como funcion estatal, pulverizada entre divetsos procesos

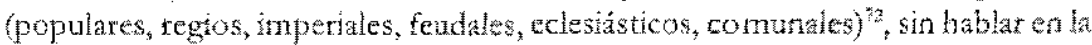

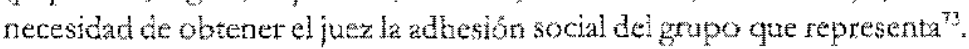

Papel importante debe ser tributado, aún, al habito escolatuco de pensar argumentar imperante entre juristas, físolos y naturalisras: el amor de las distinciones sutules y, sobré todo, ta tendencia de razonar por medio de dedtceiones de princípios preestablecidos, en detrimento de tabservación de los hechos, debería necesartamente favorecer la construcciôn de sistema probatorio totalmente apriontstico y formal, como el de las pruebas "legales ${ }^{274}$. De esa torma, se buscaba restringir el libre ejercicio

"CHONENDA, Instutución, cit, voll no 32 pág. 146.

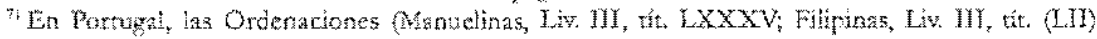

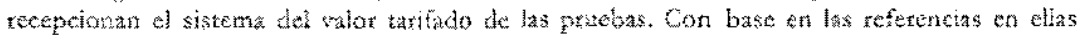
realizatos se insinuó toda la correspondiente teoris del detecho conun, estableciendose un

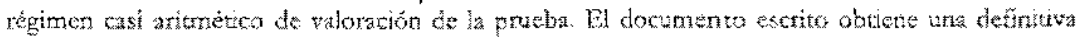
predominanch sobre la prutebastemonial. Un tesjdwo de los antiguos jurantentos itusdecisontos es constidido por "juramento keferido" o "reiterido" (Ordentones Filipinas,

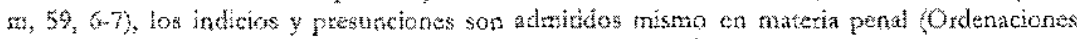

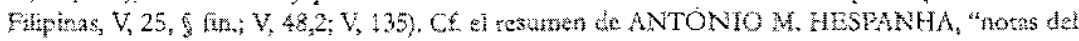

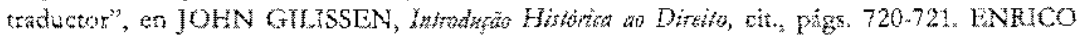
TULXO LLEMAN, en sus notas a

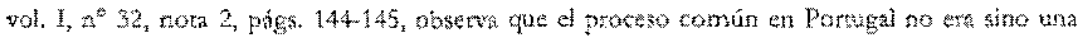
*atiedad bel proceso curopera sunque conservata forma propia. Registra tambiè la relativa

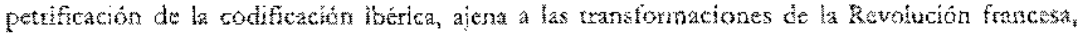
con reflejo en ba legisiacion procesa brasícha del sigio pasabo y en los Códigos estaduales.

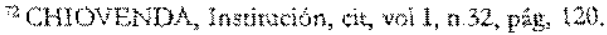

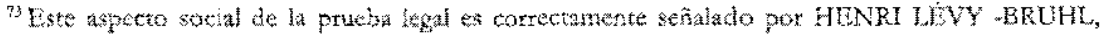

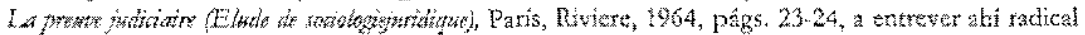
distinción on relación a la prueba cientifica

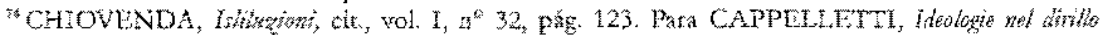

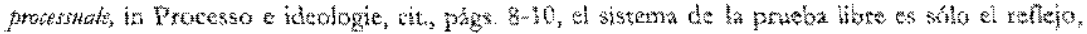
en la esfera procestl, del triunto del mêtodo de la observacton directa de los dates concretos

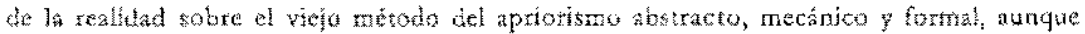

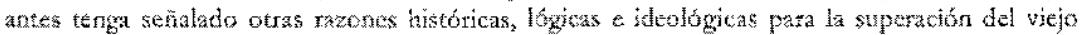

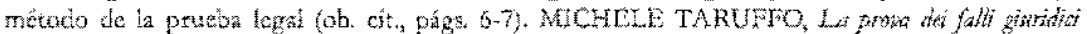

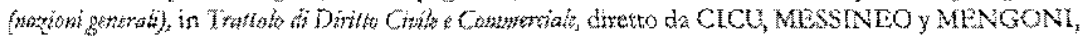

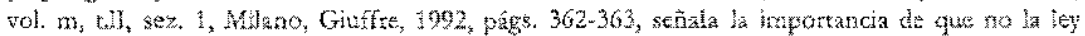

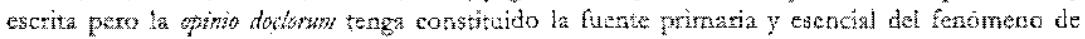

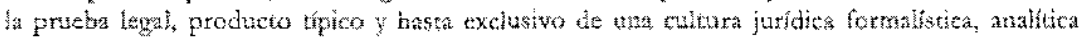


de la funciôn fudicial frente a la doctrina escolástica de la imperfecoion del bombre y de su naturaleza corrupta, asf como de la real periclitación de la honradez y de la independencia jurisdiccional en los embates políticos y económicos de aquellos tiempos ${ }^{75}$.

En retrospectiva histótica, imposible negar el gran perfeccionamiento en la administación de la justicia conquistado con la adopeción del nuevo sistema de apreciación de la prueba, especialmente frente al proceso primitivo germánico, repleto de arbituriedad y periuclo, por largamente contribuir para sustituir la superstición por el formalismo riguroso ${ }^{\text {"t }}$ y permitir el contol formal del procedimiento. En el lugar de la fuerza y del acaso, del duelo y de los juicios de dios, pasan a ser considerados elenentos bien más tacionales y humanos ". Mismo el tigor formal, señalese, encontraba plena justufficativa en las condiciones culturales y socio-económicas entonces dominantes. Imperioso reconocer, del mismo modo, gue, en sociedad de tal manera estructurada, la fijación de ciertas notmas de valoración numérica y formal de fas pruebas, aunque representara, de un lado, una especie de codificación de las desigualdader y de detemuntados periucios y superstcitones, por otro tambien exprimín una forma de barrera contra los excesos, todavía peores, que podrín ocurtir del arbitrio de los jueces y al mismo tiempo contra la decadencia de las costumbres judiciarias de la época

Este cuadro sólo vendria a alterarse con la cultura del iluminismo y la renovación del método cientifico, a incentjvar más acurada observación de los hechos y as libre investigación del brgano judicial, factor acompañado de la progresiva superación dei feudalismo y consecucnte restauración de la idea de Estado, con retejo intrediato en la concepción moderna del proceso como relación del derecio púbico, ancrementar la dimension del oficio judicial.

y categúrica, aficcionada a las sutilezas y de las complteaciones tasificadoras, y en chera medida mucho menor, fenômeno legislativo. Afirma aûn, ob. cit., pág. 363, nota 186, que en los sighos XV1 y XVI el aristotelismo tomismo deja de proporcionat los instrumentos de analisis,

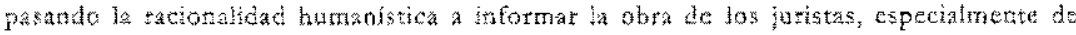

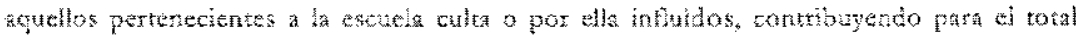
abankuno de los việos métedow.

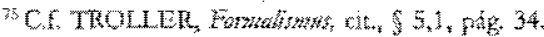

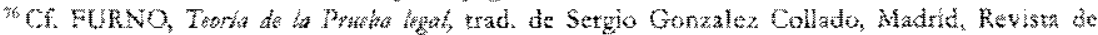

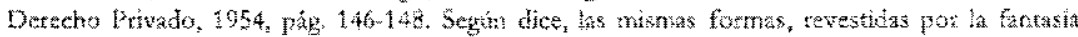
popular de un significado simbólico, se vacia más tarde de todo contendo trascedante para el derecho, sobreviviendo con valor autúnono y llevando al parodojal establecimiento de "tablas" para la apreciación de la prueba, asi como al exceso de formalismo.

"CAPPLLIETTI, a process civile italiano wel quadro della entrapposizione "civil law common

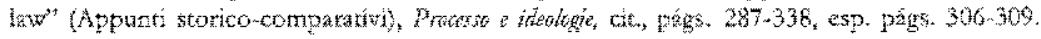

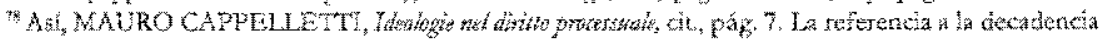

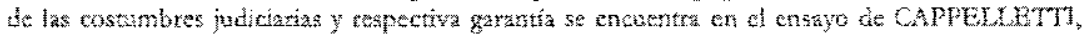
If the

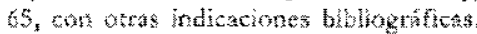


Esa línea ascendiente ganó gran incentivo con la revolución francesa, aniquiladora del viejo orden, notadamente del carácter patrimonial y corrupto de ta

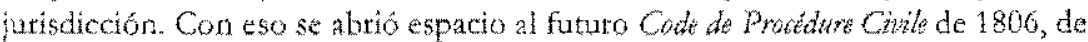
naturaleza clara y sencilla, caudatario de la oralidad y de la publicidad, del principio de Ia soberania del juez y de la agilidad de las formas, determinante por esas razones de enézicica reacción contra $\epsilon^{l}$ proceso comín en casi todos los estados eutopeos ${ }^{79}$.

Cumple, sin embargo, advertir que el sistema francés, mismo en su culninancia, no llegó a implantar plenamente el principlo de la libre apreciación de la prueba. Solamente discusiones doctrinarias posteriores, trabadas en la ocasión propicia de la elaboración de los ordenamientos procesales civiles de Alemania y de Austria, en vigor respectivamente en 1879 y 1898 , en los cuales se introdució la idea fundamental de oralidad, con todas sus consecuencias (concentración, inmediatez, inmutabilidad del fuez, ibre apreciacion de la prueba), conducitian a la definitiva superación del modelo del proceso común, de carácter escrito, diluido en innumerables términos, traguentado en múltiples prontunciamientos parciales y respectivas posibilidades de impugnación, enemigo jurado del contacto directo del juez con las partes y las pruebas ${ }^{k}$.

Además, en el pasaje del derecho común a las codíticaciones, el sistema de la prueba legal, más allá dé perder las características del fenomeno cultural y doctrinario, ganando forma normativa, sufre poderosa simplificación dejando de ser "sistema" pára comprender sólo algunos medios de prueba, con lo que adquiere fuerza ef principlo generai del "libre convencinsento"s".

Aspecto significativo, gue en gran medida colabora para mejor entender el pasaje del sistema de la prueba legal doctrinaria para la "codificada", reside en la diferencia de la apreciación realizada por el organo judicial. Si en el derecho común el sistema de la prueba legal elimimaba la discrecionariedad subjetiva del juez en la atribución de valor a los elementos singulares de pruebra an compensación la estructura del cáculo por él efectuado correspondia a la estructura de la situación probatoría especifica, generaimente cercana a la situación procesal verificada en el caso concreto. Fenómeno semejante, pero, no ocurrió con la prueba legal "codificada" o con su mayor o menor residuo en los Códigos que pasaron a surgir. Ciertamente, se ernpieza a desconocer las distinciones analtiters y complicadas entre tipos y subtipos, asi como

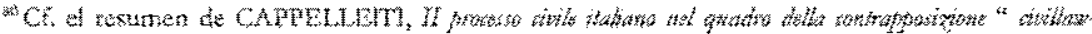

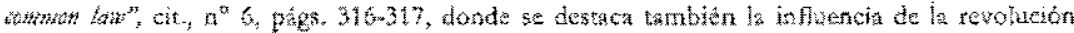
francesa y la profunda inyastigacion cientifica sobre el derecho y el proceso temano pure levada a cabo por la doertina alemana del siglo $X X X$, con relejo de las dees tunclamentales del proceso civil romano dásico en las orderaciones alemanas y austríca.

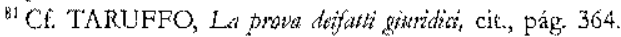

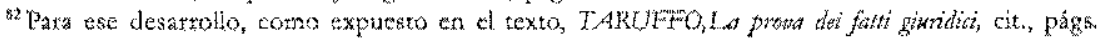
364.366
} 
Las gradaciones y fracciones de valor, por niedio de los cuales los juristas medievales buscaban racionalizar la diversidad de los casos concretes. For otro lado, sin embatgo, la prueba legal pasa a fundarse en una técnica mucho más rígida y formalística, aunque con grandes características simplificadoras, en la medida en que impone resultados vinculables $\mathrm{c}$ incontestables a determinados tipos de prueba. Se elimina asi el problema de juicio de hecho, lo que no ocuría con el sistema de la prueba "lega" del derecho común, aunute procurara éste veducir el nargen de vartabilidad subjetva. Intrinsecamente, por consiguiente, en un primer momento se pasa de la racionalización del sistema de las preebas para la formalización vinculable de la eficacia de la prueba individuat ${ }^{42}$.

La cvolución posterior se manifiesta totalmente en el sentido de iberar cada vez más el juez de esas cadenas formales, de suerte a posibilitarle más libre apreciación de la prueba. Se retoma, así, a la racionalización del sistema, pero en otro nivel cualitativa, con la manifiesta intención de hacer cesar los vinculos formales en la apreciación del material probatorio, mediante predominancia de la verdad enoírica extraida de los hechos de la causa por medio de la lógica y de criterios científicos ${ }^{83}$.

Clato est: tambien, que en el problema del control de la libre apteciacion de la prueba, identificase de forma aguda un evidente conflicto entre la libertad del organo judicial y el derecho de ciudadania procesal.

Indubitable, por un lado, que no 32 muestra admisible, en la presente pasantáa civilizarotia, cualquier retroceso en el sentido de tarifar la apreciacion del hecho por el juez ${ }^{84}$. Semejante retroceso traeria como inamovible consecuencia un indeseable

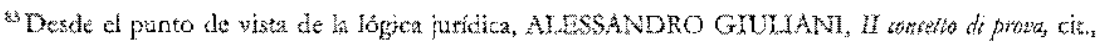

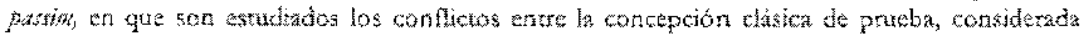

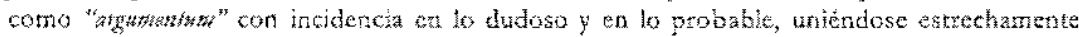

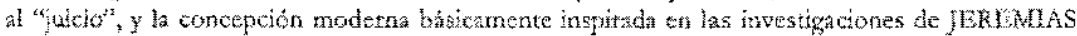

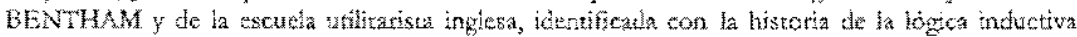

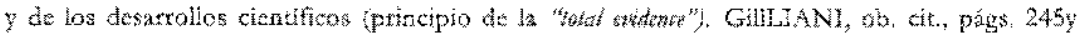
shyutentes, defiende la tesis de que la concepcion de la prieba se basa cn la legalidad, con

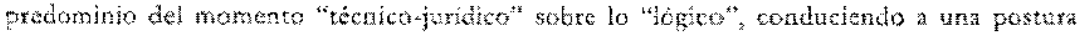

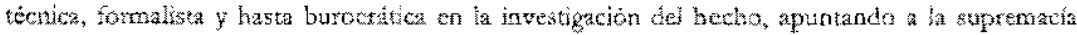

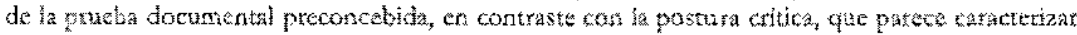
el procero de formacion del juicio en las experienchas procesales unicias a ia prueba testimonial, en el camino de la tradicion tópico - retónica.

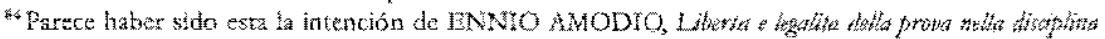

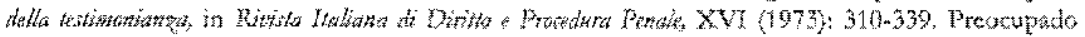
con la "degeneracion" de la pretica judicial peral haliana, propone una "xiscoperta" de las *egla probatorias legales como instrumentos destinados a lisnitar en sentido negativo los

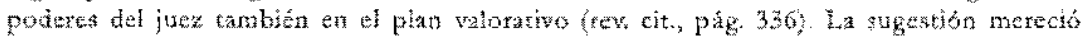

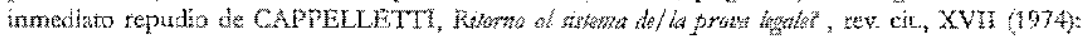
$139-141_{*}$ combatiendo las generalizaciones peligrosas y ci formalimo de esa posicion, con

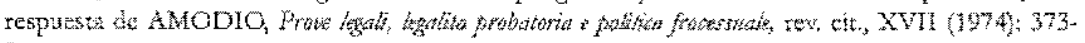
376. 
incremento del formalismo, apartando el juicio de la verdad real o material, ideal que debe ser siempre buscado.

Por otro lado, se impone adoptar, como salvaguardia para mejor establecimiento de la verdad y paralelo resguardo contra el abuso de la libertad judicial a respecto, el control de la sociedad imbuida de valores democráticos.

En otras palabras, la cooperación ejerce también aquí un papel relevante. Tal se instrumentaliza por medio de los principios, garantías y técnicas formadores del propio proceso. Y, realmente, visan ellos, exactamente, no sólo facilitar el trabajo judicial, como también incrementar la colaboración de las partes, a ejemplo de la inmediatez en el debate y en la recepción de la prueba oral, del contradictorio y de la presencia de los interesados en la producción de las pruebas ${ }^{85}$. Al mismo tiempo, el deber de motivar la sentencia, el atendimiento a las formalidades establecidas en ley para la realización de la prueba, la publicidad del procedimiento, la posibilidad de recursos en general y el duplo grado de jurisdicción, sirven como resguardo al arbittio judicial, por limitar el carácter "personal" de la decisión y mejorar su objetividad ${ }^{86}$.

6. Finalmente, cumple examinar cuestión de gran relevancia teórica y práctica, que respecta a la conveniencia o no de concederse al órgano judicial poderes para disponer, más o menos libremente, sobre el derecho de la parte. En esa materia sobresale con fuerza la clara tensión entre el derecho procesal y el derecho material, visto que corre éste el riesgo de sucumbir en virtud de consideraciones puramente formales ${ }^{87}$. Se trata, intrínsecamente, de investigar el enlace existente entre la actividad

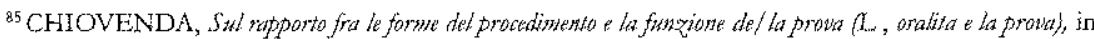
Saggi di Diritio Processtute Cinte, vol. I1, Roma, 1931, Foro Italiano, págs. 197-225, esp. pág. 225, señala con agudeza que la libertad de convenciniento del juez desea a la luz de la audiencia, corrompiéndose y muriendo en los laberintos del proceso escrito. Para CAPPLLLETf, La testimontioná, cit, vol. I, págs, 130 y siguientes, 139,164, se muestra indisociable la interdependencia recíproca entre inmediación, oralidad y libre apreciación de la prueba, residiendo el sentido mayor de la inmediación exactamente en la libre valoración de la prueba, porque a la prueba legal no interesa el modo como es realizada. Asi también GERHARD W ALTER, Libre apreciación de la prneba cit., $\$ 15$, págs. 363 y siguientes.

${ }^{86}$ Observa agudamente GERHARD WALTER, Libre apreciacion de la prneba, cit, págs. 94-95, haber existido siempre esos principios y garantías cuando la apreciación de la prueba no estaba reglada, desapareciendo tan pronto predominaba la teoría de las pruebas legales. Segundo TARUFFO, La prova dei fatti giuridici, cit, págs. 376-377, el deber de motivación, dentro de esa concepción racional del convencimiento $4 \mathrm{el}$ juez, asume exacto y preciso significado, de modo que pueda ser controlado externamente el órgano judicial y compelido asi a justificar sus elecciones en el juicio de hecho con argumentos tacionales. Sobre el significado de la publicidad para la libre apreciación de la prueba, aún GERHARD W AL TER, Libre apreciación de la prneba, cit, págs. 380-385. Sobre la cuestión del control endógeno del raciocinio judicial, C. A ALVARO DE OLIVEIRA, Livre Apretiagáo da Prova: perspectivas atuatis, in La Prneba -Homenaje al Maestro Hemando Devis Echandia, Colombia, Universidad Libre, 2002, págs. 599-613, esp. págs. 610.613.

${ }^{87}$ Como bien señala ALOIS TROLLER, Formatismus, cit. \$5.1, pág. 31. 
judiéal y el principio dispositivo en sentido impropio, aún măs que la participación exarcebada del órgano judicial puede conducir a abuso. "Y eso porque el pricipio dispositivo se revela fundamental pata la exacta apreciación de la dimensión de los podetes de iniciativa del juez y de las partes ${ }^{\text {gh }}$.

Consutuye principio asentado de latga fecha caber a la patte la exclusiva inciativa

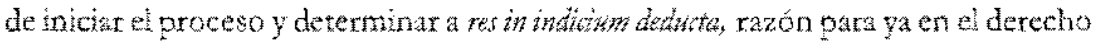
romano medieval tener asumido foros de ciudadanía la máxíma tradicionai nena

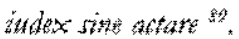

Razones de politica judiciaria, en que gana telieve el valor fundamental de la imparcialidad, deteminan la conveniencia del total receso del organo judicial tanto del pedido como de ha indicación de la caus zetezis poco importando la naturaleza del derecio en causa, salvo contadas excepciones ${ }^{3 / 2}$.

Fundamento diverso, hoy un tanto descuidado y poco mencionado, consiste en la propia beendad del individuo, cuya iniciativa en el acturar ante la administración

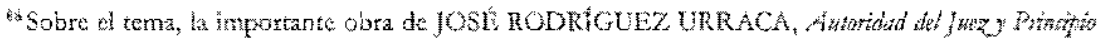

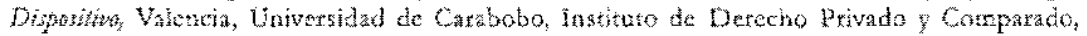

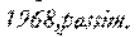

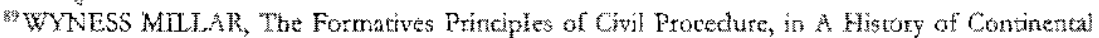

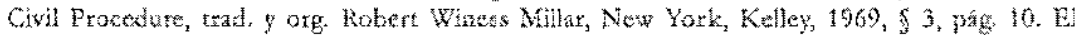
proodimenta civil roman, señm ARTHUR ENGELAANN, The Roman Procedure, en

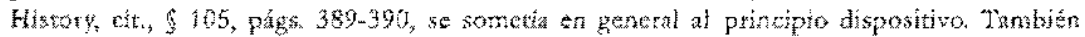

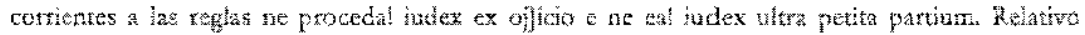
al desartollo histrico de esas maximas en el derecho comón, ver GEORG WILHEN WETZEL,

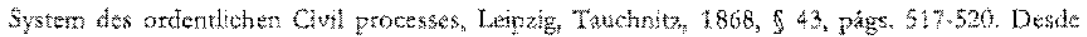

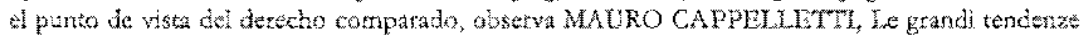
evolutive def processo civile, cit, pázs. 182192 , la idatica aceptación de tales reglas an todos

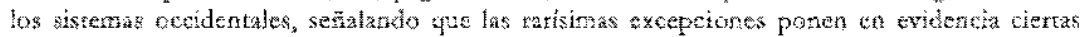

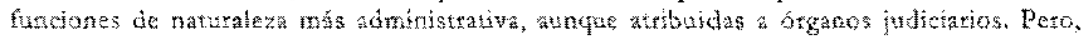
como bien aclat JAYME GUASP Juez y hechos en al pereso cwil. Una critica del tetacho de disposición de las partes sobre el material de hecla del proceso, Barcelonat Bosch, 1943, pág. 34, no se verifica plena equivalexcia entre las expresiones nemo ivdex sine actore te ne procedal iudex ex ojjeio. Atuque ambas expresen limitaciones al espontaneo desartolio de la

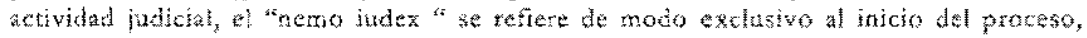
menteas el "ne procedal index" abarea tembién, o puede abartar todos los actos de impulso

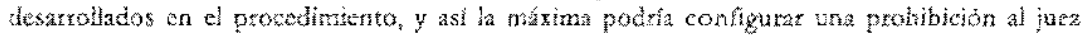
te hacer avanzar el proseso a través de los diversos estagios a ser recorridos hasta la decision frnal,

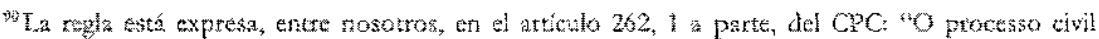

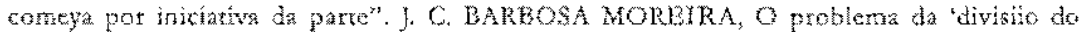
smbaho' tntre juz e partes: aspectos terminologicos, Revista de Processo, 41 (1986)7-14 bien evidencia como la incidencia de esa notma no se testinge al tertiotio to las derechos disponibles, pues, en casos excepcionales mismo siendo indisponible et derecho, puede el jue brasilefo inctar de oficio el procesa. 
judicial se impone totalmente independiente del poder estatal el ciudadano ibre debe quedarse plenamente desimpedido para alzar el vuelo más conveniente en la defesa de sus derechoss".

Se asocian a ce condicionamiento de la jurisdicción a la provocación de la paite, actualmente denomina do principio de la demanda, el procipio de la excepción material (exofthono iuris), el de no poder el organo judícial conceder tutela inferior, más allá o de naturateza diversa de la contenida en el pedido de Ja parte (ne eatjudex utra petita partium), el principio de la impugnación de la sentencia sólo por las partes y el principio da la disponibilidad privada del proceso, para formai en su conjunto lo que se convencionó denominar en doctsina "principio disposirivo" en sentido material o propio . Todos representan limites formales a los poderes de que goza el organo judicial, en la verdad la mayor barrera formal a su actividad.

Otro aspecto reletatte en esa senara, fundamentalmente informado por la economia procesal, desemboca en la inatrerabilidad del pedido y de la causa de pedir, de fuerte tradición en el derếcho brasileño\%. Resalta aqui el interés público en que la demanda tráda a juicio sea recuelta lo más rápidamente posible, y tambien el propio carácter ordenador del proceso, a correr el riesgo de transformarse en una trama inextricable dejándose al arbitrio de las partes el cambio del pedido o de la causa de pedir a cuaiquier hora.

El interés público se manifiesta en el sentido de que la gestión de la fusticia se realice con habilidad y funcionalidad, objetivo que podráa quedarse internmente comprometido se permitida la alteración, pues la nueva demanda ba de ser necesariamente discutida en el proceso, teabréndose incluso la postbildad de prueba

\footnotetext{
"Esia forma del problema fue subrayuta de modo adectato por HANS FRThCHL, apud, A

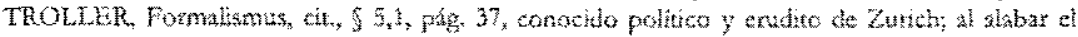
principio dipposive an estos teminos: "Constituye uno de los mas bellos derechos del ciudadano libe que, habiendose tortade sa cuestion litigiosan no rexeste pedir al juez su gracia, como el eschato se dedica a su senot en el castllo, pero delante da el se defiente, en oposición a su adversatio, y para eso pueda constieuir un abogado - l l locz no debe estar ahi como un administrador secreto, pero como el hombre a quien abe thono de decidir sobre relaciones juridicas tornadas litigiosas ente ciudadanos libres."

"2 Asi, MAUROCADPELLETT, Le grandi tendenze ewolitize, cit, págs. 182m191. Con razón, ANTONLO

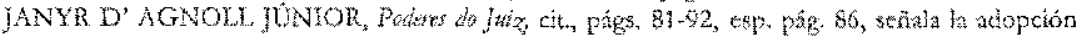
por el derecho posivivo brasileño del "principio dispostivo" en sentibo matctial o ptopio,

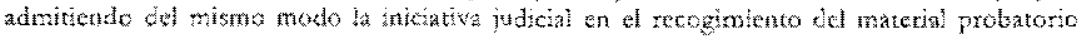

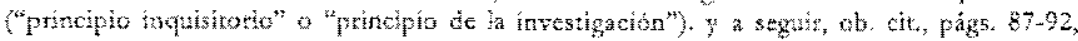
demuestra sa poposicton de forma convincerite on inditacion te divetsos dispositivos conteritas as al Clo de 73 .

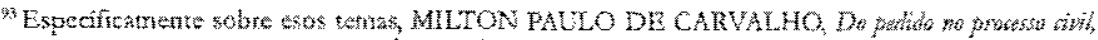

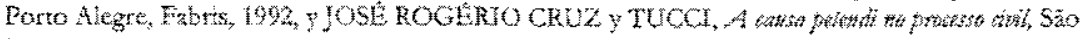
Pato, $\mathrm{RT}, 1993$
} 
a respecto, so pena de la innovación causar sorpresa y violar el principio de lo contradictorio ${ }^{94}$.

Sin embargo, la experiencia histónica más modena estableció brechas en cse rigoristno fomal, buscando coordinarto con el principio de la economía procesal, prestando as mayor agilidad al proceso.

Tipico ejemplo de esta onientacion es reptesentado por el 263 de la Ordenariza Procesal alcmana, en la redacción de novela de 1933 , al permitu la modificación de la demanda, independiente de consentimiento del adversario, si entendido por el Tribunal estar atendido el requisito de la "oportunidad" (Sabienlichketit). La doctina gernáníca considera decisivos para la aplicación de ese concepto el interés público en el rápido desarrollo del proceso o las exigencias de la economia del juicio.

En el misno camino, el 235,3 , de la Ordenanza Procesal austríaca, antoriza al juez pemitir la modificacon de la denanda si no es de temer "un retardo releyante" y "un agravamiento" en el desartollo del procest.

También la Ordenanza Ptocesal de Berna, \$94, admite la alteración de la demanda o de la reconvención, sin el consentimiento de la parte contraria, si apoyada en causa de pedir semej ante a la anterior pretensión o conexa con la ci ercida, desde que el fuez considere que no haya ocurrido de ahi considerable agravamiento o tardanza en la marcha de la causa ${ }^{\circ}$.

En tema de alteración del pedido, mantenida la misma causa de pedir, la ley alemana es aún más libetal, pues, consonante a los tres incisos del 264 de la Ordenanza procesal, las hipótesis sigutentes no configuran alteracion de la denanda: I- puro y simple suplemento o aclaracion de las alegaciones de orden fáctica o juridica; II extensión o limitación del pedido de fondo o relativamente a algin crédito accesorio; III - , en vittud de modificación ocurrida posteriormente, en hugar del objeto

\footnotetext{
Wha doctina de modo general juatica el vedumiento de alteración de ha demagda con base en

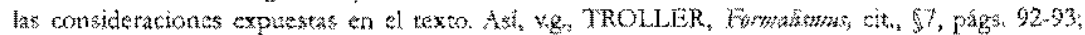

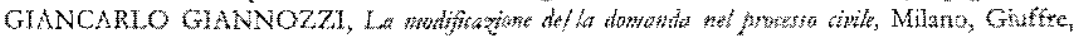

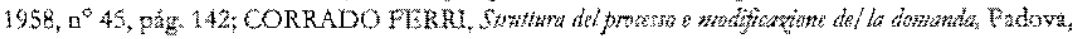
Cxdam, 1975, ratag, 6, seralando sún el principio de la concentración y la necesidne de ser

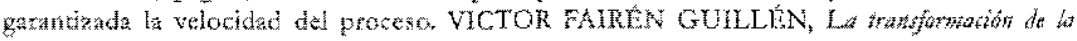

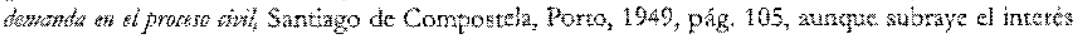
publica en la buena marcha del proces, pondex que, en muchar acasiones, hateracion de Ja dernanda puede significar una gran conomia ptocesal, cvitundose inuti y cata duplicidat.

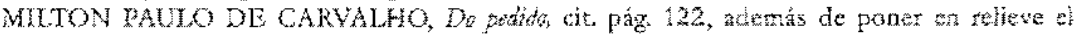

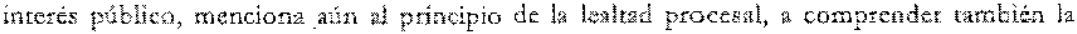
colaboración clara y pecisa de los hechos y fandamentos furtucos por atrbas las partes.

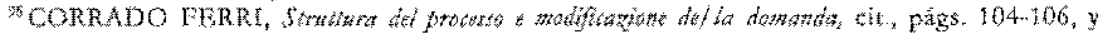

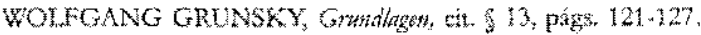

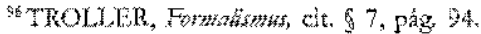


otiginatiamente exigido es pleiteado un otro objeto o interés. Consonante autorizada Fuente doctrinaria, en el primer caso inexiste conceptualmente cualquier modificación, pues, a pesar de ja alteración de las considetaciones de hecho y de derecho, el derecho ejercido permanece to mismo. En el segundo, es comprendido el pieito de intereses de la deuda ya a forada por d autor, en el curso del proceso asícomo la transformación de acción declaratoria en condenateria. Se admite también la petición de pretensiones resultantes de la misma causa de pedir, de las cuales sólo una habia sido aforada. Por último, se acentúa cque el inciso III concierne a alteraciones materiales ocurtidas dutante el proceso, a ejemplo del perecimiento de la cosa durante la litispendencia, permitiendose el sucesivo pedido de pérdidas y daños en el mismo proceso ${ }^{4 \%}$.

En esa míma perspectiva se insicre la interesante y onignal selución preconizada en la amplia y profunda reforma introducida en el proceso civil portugtés ocurtida en 1995 y $1996^{\text {s }}$, en que se faculta, mismo sin concordancia de la otra parte (CPC portugués, att. 273 , incisos 1 a 6 , "a" la alteracion o ampliación de la amtsat de pediren la réplica, si el proceso adnitirla, o que la alteración o la amplíación sea consecuencia de confesión hecha por el reo y acepta por el auter; b) la al teración o ampliación del jecibo en la réplca, pudiendo, además de eso, el autor, an cualquier instancia, reducir el pedido y amplinaro hasta el encerramiento de la discusion on $1^{\circ}$ grado de jurisdicción si la amplación consistir en desarrollo o consecuencia del pedido primitivo; of la ampliacion o alteración del satha de aplicación de sancion pecuniaria compulsoria en el caso de obligaciones de prestación de hecho infungibles, al abrigo de lo dispuesto en el art. 829, I, del código Civil, respetados los términos del art. 273,2, del CPC; d) al autor teguerir en las acciones de indemnización fundadas en responsabilidad civil, hasta el encertamiento de la audiencia de discusión y jucio en $1^{\circ}$ grado' de jurísdicción, la condenación del reo en forma de renta vitalicia o temporaria (art.567 del Código Civil), mismo que inicialmente tenga pedido la condenación de aquel en cuantía

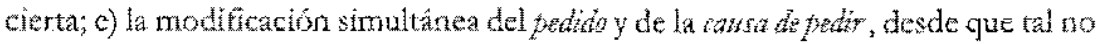
suponga convolución para relación jutidica diversa de la controvertida.

Habiendo acuerdo de las partes, ya la reforma de 1967 , dando nueva redacción al art. 272 del CPC portugués, antorizara la alteración o ampliaciòn del pedido y de la

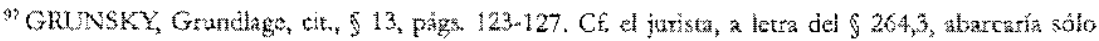

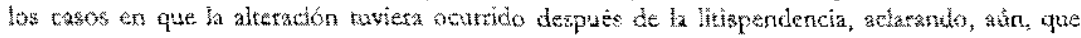

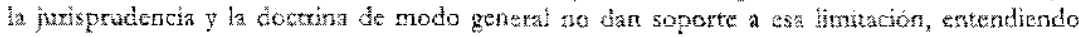
admiable ha alteracion tambièn cuando in cosa tenga perecido antes de la proposición de la acción, si desconocido el hecho del autor.

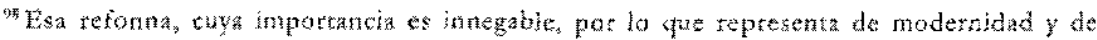
adecuación a las detenninantes axílógicas del proceso actual trascurto de la profunda alteración decenumata por los ya mencionados decretaswley $32 \%-A$, de 12 de diciombre de

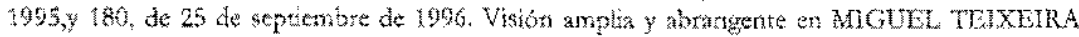

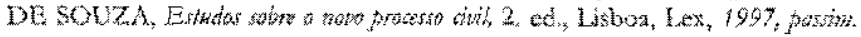


causa de pedir en cualguier instancia del proceso, tamo en $1^{\circ}$ como en $2^{\circ}$ grado de juxisdicción, salvo si ocurtiera pertubación inconveniente de la instrucción, discusión y juicio del pleito"

El derecho brasileño se muestra bien más rigido, ya que realizada la citación se prohibe al ator modificar el pedido o la casa de pedir, sin el consentimiento del reo (art. 264, 18 parte, del $\mathrm{CPC}$. Además de eso, después del saneamiento del proceso en ninguna hipótesis será permitida tal alteración (art. 264, 28 parte, del $\mathrm{CPC}$. Nada impide, pero, dentro del permisivo legal del articulo 284 del CPC, anter de la citación y mismo por orden del juez, $\vee$, la adaptación dela petición inicial de accion ejecutiva pata proceso de conocimiento, o viceversa, pues, conforme el attículo $264 \mathrm{del} \mathrm{CPC}$, el autor puede promover semejante modificacion ${ }^{10}$

De cualquier modo, como bien sernala

Desde el punto de vista cooperativo, en el periodo actual de la historia brasieña, ya está más que en tiempo de empezar a pensar en la reforma de la legislación procesal, para permitirse la alteración del pedido y de la causa de pedir en los téminos de la reciente reforma portuguesa, De esa forma, se estimularía una vez más el descable diálogo entre el órgano jadicial y las partes, quebrándose al mismo tiempo un formalismo excesivo, que no tiene más razon de ser.

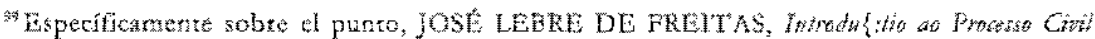

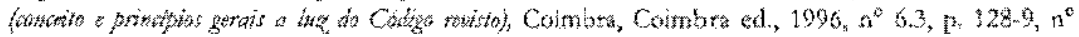

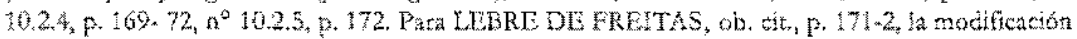
simultánea del pedido y de la causa de pedir es pasibie no solo tuando algunos de los hechos que integins la nueva causa de pedir cotncidan con hechos yue integran la crasa de peelir originativ o la causa de pedir zeconventional o funcien exeepcioses deducidas, pero tanbién cwanto, por lo menos, el nuevo pedido se repotte a una rełación material dependiente o

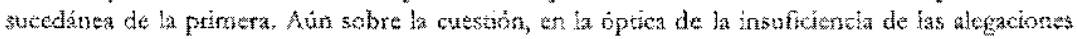
$y$ del princigio disposituo, las interetantes $y$ relkvantes observacionet de PAUA COSTA E

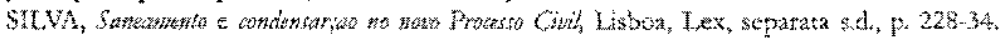

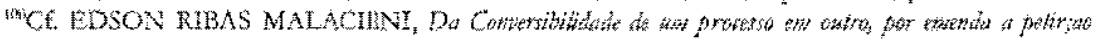

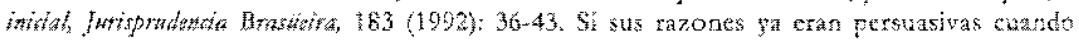

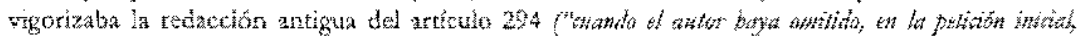

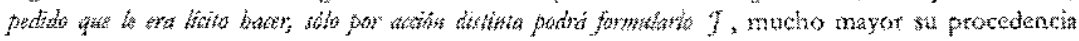

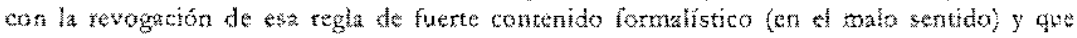
reptesentaba acogimiento extremo entre nocotros del principio de ha ewentualiad. En la

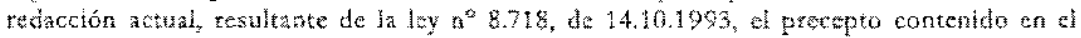

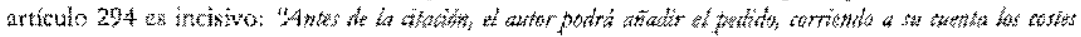

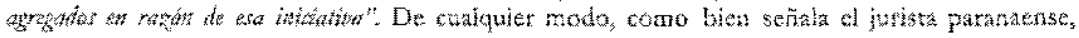
el apoyá de la cuestion resike en que ol pedido la causa de pedir stempre pueden sem modificados antes de la citación.
} 